\title{
Are the Transient and Equilibrium Climate Change Patterns Similar in Response to Increased $\mathrm{CO}_{2}$ ?
}

\author{
DANQING HUANG \\ School of Atmospheric Sciences, Nanjing University, Nanjing, China
}

Aiguo DAI

Department of Atmospheric and Environmental Sciences, University at Albany, State University of New York, Albany, New York

JIAN ZHU

State Key Laboratory of Hydrology-Water Resources and Hydraulic Engineering, Hohai University, Nanjing, China

(Manuscript received 8 October 2019, in final form 7 July 2020)

\begin{abstract}
After a $\mathrm{CO}_{2}$ increase, whether the early transient and final equilibrium climate change patterns are similar has major implications. Here, we analyze long-term simulations from multiple climate models under increased $\mathrm{CO}_{2}$, together with the extended simulations from CMIP5, to compare the transient and equilibrium climate change patterns under different forcing scenarios. Results show that the normalized warming patterns (per $1 \mathrm{~K}$ of global warming) are broadly similar among different forcing scenarios (including abrupt $2 \times \mathrm{CO}_{2}$, $4 \times \mathrm{CO}_{2}$, and $1 \% \mathrm{CO}_{2}$ increase per year) and during different time periods, except for the first 50 years or so when warming is weaker over the North Atlantic and Southern Ocean but stronger over most continents. During the first 200 years, this consistency is stronger over land than over ocean, but is lower in midlatitudes than other regions. Normalized precipitation change patterns are also similar, albeit to a lesser degree, among different forcing scenarios and across different time periods, although noticeable differences exist during the first few hundred years with smaller increases over the tropical Pacific. Precipitation over many subtropical oceans and land areas decreases consistently under different forcing scenarios and over all time periods. In particular, the transient and near-equilibrium change patterns for both surface air temperature and precipitation are similar over most of the globe, except for the North Atlantic warming hole, which is mainly a transient feature. The Arctic amplification and land-ocean warming contrast are largest during the first 100200 years after $\mathrm{CO}_{2}$ quadrupling but they still exist in the equilibrium response.
\end{abstract}

\section{Introduction}

Global climate models have been widely used to quantify climate response to recent and future emissions of greenhouse gases (GHGs) from human activities. Both the transient and near-equilibrium responses are used to quantify the impact of increasing GHGs on surface air temperature (SAT), precipitation $(P)$, and other fields. For example, Mitchell et al. (1990) showed broadly similar surface warming patterns, such as greater warming at northern high latitudes, from a transient simulation and a slab-ocean run with a doubling of atmospheric $\mathrm{CO}_{2}$, with the latter representing an equilibrium response. However,

Corresponding author: Aiguo Dai, adai@albany.edu the warming magnitude at a given time with the same amount of $\mathrm{CO}_{2}$ increases during a transient simulation (i.e., with gradual $\mathrm{CO}_{2}$ increases) is expected to be smaller than the corresponding equilibrium response, particularly for the North Atlantic and the Southern Ocean (Manabe et al. 1992; Manabe and Stouffer 1994; Zhang 2011; Yoshimori et al. 2016). This is because the heat stored in subsurface oceans will continue to cause surface warming even after $\mathrm{CO}_{2}$ stabilizes (Meehl et al. 2005).

SAT and $P$ change patterns, often normalized by the global-mean temperature change, may depend on regional feedbacks (Kiehl 2007), regional ocean heat uptakes (Rose et al. 2014; Rose and Rayborn 2016), and changes in clouds and other factors (Zhou and Chen 2015). Many studies showed that SAT and $P$ change 
patterns may evolve with time during long simulations. For example, Armour et al. (2013) showed different warming patterns at high latitudes during the first 100 years of an abrupt $2 \times \mathrm{CO}_{2}$ experiment; Andrews et al. (2015) showed noticeable warming differences (up to $1 \mathrm{~K}$ ) over many areas between the first 20 years and years 21-150 in CMIP5 $4 \times \mathrm{CO}_{2}$ runs; Yoshimori et al. (2016) found that surface warming is less over the Southern Ocean (by 0.4-1.0 K) and the Arctic Ocean (by $0.2-0.4 \mathrm{~K}$ ) but more (by $0.2-0.4 \mathrm{~K}$ ) over some other oceans in a transient run with $1 \% \mathrm{yr}^{-1} \mathrm{CO}_{2}$ increases around the time of quadrupling than that from a nearequilibrium state from a multi-millennium abrupt $4 \times$ $\mathrm{CO}_{2}$ simulation; $\mathrm{He}$ and Soden (2016) showed that the warming and the precipitation increase at high latitudes strengthen near the end of a 150 -yr simulation with an abrupt $4 \times \mathrm{CO}_{2}$ increase; and Paynter et al. (2018) showed noticeable differences in warming patterns during years $0-10,11-350$, and thereafter in abrupt $2 \times \mathrm{CO}_{2}$ experiments by two fully coupled climate models. On the other hand, in the model simulations from phase 5 of the Coupled Model Intercomparison Project (CMIP5; Taylor et al. 2012) under different representative concentration pathways (RCPs) (Meinshausen et al. 2011), which are transient forcing scenarios, SAT and $P$ change patterns in the twenty-first century are found to be fairly similar across models (except for certain tropical and other regions) and scenarios (Collins et al. 2013; Leduc et al. 2016; Tebaldi and Arblaster 2014), but this similarity degrades over a multicentury period (Tebaldi and Arblaster 2014).

These previous studies suggest that the SAT and $P$ response patterns vary with time after an abrupt increase in atmospheric $\mathrm{CO}_{2}$, especially during the first few decades as the system rapidly responds and adjusts to the greatly increased $\mathrm{CO}_{2}$ level. They also suggest that the short-term transient and long-term nearequilibrium response patterns may differ for SAT and $P$. However, a systematic, comprehensive examination of how the response patterns for both SAT and $P$ evolve with time is still lacking, especially for $P$ change patterns since most previous studies have focused only on the warming patterns. In particular, the SAT regional differences mentioned above were often based on averages over 10-30 years from one single simulation, in which realization-dependent internal variations can contribute significantly to the apparent differences averaged over a few decades over many regions, especially for precipitation (Dai and Bloecker 2019).

Since natural climate variability often induces large precipitation variations, estimating the forced signal from noisy precipitation data is more challenging than for temperature (Hawkins and Sutton 2011; Deser et al. 2012; Huang et al. 2013, 2018; Dai and Bloecker 2019).
Further, the GHG-induced $P$ change patterns are more complicated than those for temperature (Tebaldi and Arblaster 2014; Leduc et al. 2016), and they have not been fully understood despite many proposed mechanisms (e.g., Chou et al. 2009; Dai et al. 2018, 2020b).

Here, we aim to answer the following two questions using long-term simulations with the Community Earth System Model version 1.2.1 (CESM1.2.1) (Hurrell et al. 2013), together with the extended multicentury simulations from CMIP5 and the abrupt $4 \times \mathrm{CO}_{2}$ multimillennium simulations from three other coupled models:

1) Are the transient and near-equilibrium change patterns for SAT and $P$ similar under increased GHGs?

2) What differences exist between the transient and equilibrium change patterns for SAT and $P$ ?

Answers to these questions have major implications for climate research. For example, they may tell us whether it is appropriate to compare today's transient climate change patterns (which may have different land cover and characteristics of external forcing) to past paleoclimate states such as the early Pliocene warm climate (4-5 million years ago) (Burls and Federov 2017), which represents an equilibrium state. Further, what we have observed so far and what the models projected to occur in the twenty-first century are all transient climate changes. The answers to the above questions can tell us whether these transient change patterns will persist into the future when we stop emitting GHGs.

While the surface warming patterns over different time periods have been examined in many recent studies as discussed above, the focus of these studies has been on the sensitivity of global-mean temperature to radiative forcing and how that sensitivity varies with different SAT response patterns. These previous studies (e.g., Armour et al. 2013; Yoshimori et al. 2016) often showed the SAT change patterns from a single run with an abrupt $\mathrm{CO}_{2}$ forcing during the early adjustment period that includes the first few decades to the first $\sim 150$ years, during which one would expect the SAT response patterns to change after a large and sudden $\mathrm{CO}_{2}$ increase. Thus, these early change patterns may contain substantial transient features that vary with individual runs and should not be confused with the real forced longterm response. Our focus here is on the externally forced SAT and $P$ change patterns outside the initial adjustment period (the first 100-200 years) in an abrupt $\mathrm{CO}_{2}$ change experiment, and in a transient climate simulation with gradual $\mathrm{CO}_{2}$ increases. The first 100-200 years of the abrupt $2 \times \mathrm{CO}_{2}$ and $4 \times \mathrm{CO}_{2}$ experiments reflect the initial adjustment to a large and sudden $\mathrm{CO}_{2}$ increase, which is unrepresentative of the real world's $\mathrm{CO}_{2}$ change of $\sim 1 \% \mathrm{yr}^{-1}$. The warming patterns examined here are 
TABLE 1. The nine CMIP5 models used in this study. The first realization (r1i1p1) from each model was used.

\begin{tabular}{|c|c|c|}
\hline Model name & Institute (country) & Atmosphere resolution \\
\hline BCC-CSM1-1 & $\begin{array}{l}\text { Beijing Climate Center, China } \\
\text { Meteorological Administration (China) }\end{array}$ & $128 \times 64$ \\
\hline CCSM4 & $\begin{array}{l}\text { National Center for Atmospheric } \\
\text { Research (United States) }\end{array}$ & $288 \times 192$ \\
\hline CNRM-CM5 & $\begin{array}{l}\text { Centre National de Recherches } \\
\text { Meteorologiques/Centre Europeen de } \\
\text { Recherche et Formation Avancees en } \\
\text { Calcul Scientifique (France) }\end{array}$ & $256 \times 128$ \\
\hline CSIRO-Mk3.6.0 & $\begin{array}{l}\text { Commonwealth Scientific and Industrial } \\
\text { Research Organization and the } \\
\text { Queensland Climate Change Centre of } \\
\text { Excellence (Australia) }\end{array}$ & $192 \times 96$ \\
\hline GISS-E2-H & $\begin{array}{l}\text { NASA Goddard Institute for Space } \\
\text { Studies (United States) }\end{array}$ & $144 \times 89$ \\
\hline GISS-E2-R & $\begin{array}{l}\text { NASA Goddard Institute for Space } \\
\text { Studies (United States) }\end{array}$ & $144 \times 89$ \\
\hline HadGEM2-ES & $\begin{array}{l}\text { Met Office Hadley Centre (United } \\
\text { Kingdom; additional HadGEM2-ES } \\
\text { realizations contributed by Instituto } \\
\text { Nacional de Pesquisas Espaciais, } \\
\text { Brazil) }\end{array}$ & $192 \times 145$ \\
\hline IPSL-CM5A-LR & Institute Pierre-Simon Laplace (France) & $96 \times 96$ \\
\hline MPI-ESM-LR & $\begin{array}{l}\text { Max Planck Institute for Meteorology } \\
\text { (Germany) }\end{array}$ & $192 \times 96$ \\
\hline
\end{tabular}

relevant to climate sensitivity (Dai et al. 2020a), but a detailed analysis of the linkage is beyond the scope of this study. Also, for reasons stated above, we focus on the response patterns during the transient periods and for the near-equilibrium state, rather than the patterns over different warming amounts, even though the latter may be relevant to climate sensitivity research.

\section{Model experiments and method}

We ran the CESM1.2.1 (Hurrell et al. 2013), with CAM4 as the atmospheric model on a $2.5^{\circ}$ longitude $\times$ $\sim 1.875^{\circ}$ latitude atmospheric grid and the ocean and sea ice components on $\mathrm{a} \sim 1.12^{\circ}$ longitude $\times 0.47^{\circ}$ latitude grid. Three experiments were carried out: one with an instantaneous quadrupling of the preindustrial $\mathrm{CO}_{2}(4 \times$ $\mathrm{CO}_{2}$, with $\mathrm{CO}_{2}=4 \times 284.7=1138.8 \mathrm{ppmv}$ ) and then the model was run for 1000 years, one with an instantaneous doubling of the preindustrial $\mathrm{CO}_{2}\left(2 \times \mathrm{CO}_{2}\right)$ and run for 500 years, and one with a $1 \% \mathrm{CO}_{2}$ increase per year $(1 \%$ $\mathrm{CO}_{2}$ ) for 235 years (with atmospheric $\mathrm{CO}_{2}$ level reaching $2950.6 \mathrm{ppmv}$ ). A preindustrial control run (PiControl) for 151 years with the same model configuration was also done to provide the baseline for calculating the SAT and $P$ changes.

For comparison, we also analyzed the ensemble mean of the extended simulations from nine CMIP5 models
(Table 1; Taylor et al. 2012) under the extended RCP8.5 (ECP8.5) emissions scenario up to 2300 (Meinshausen et al. 2011). Atmospheric $\mathrm{CO}_{2}$ increases until around 2250 and then stabilizes in these simulations (van Vuuren et al. 2011). Thus, these extended simulations still represent mostly transient climate response to increasing $\mathrm{CO}_{2}$ and other greenhouse gases, although the warming rate and thus precipitation change rate should be smaller in the twenty-second and twenty-third centuries than in the twenty-first century. Before calculating the ensemble mean, all the CMIP5 model outputs were regridded onto a $2.5^{\circ} \times 2.5^{\circ}$ longitude-latitude grid by assigning the original model values to fine $\left(0.1^{\circ}\right)$ grid cells and then averaging the fine grid cells onto the target $2.5^{\circ}$ grid boxes. The SAT and $P$ changes are relative to the PiControl run climatology for the CESM1.2.1 and the historical (1970-99) climatology for the CMIP5 ensemble mean.

We also obtained and examined 10 multi-millennium simulations from the long run project (https:/data.iac.ethz.ch/ longrunmip/; Rugenstein et al. 2019). Many of these simulations only had $\leq 3000$ years of simulation that did not reach an equilibrium state. As a result, here we only included three long abrupt $4 \times \mathrm{CO}_{2}$ simulations from MPI-ESM-1.1 (for 4458 years, on a $1.875^{\circ}$ longitude $\times \sim 1.875^{\circ}$ latitude grid), GISSE2-R (for 5000 years, on a $2.5^{\circ}$ longitude $\times 2.0^{\circ}$ latitude grid), and CESM 1.0.4 (for 5900 years, on a $2.5^{\circ}$ longitude $\times$ $\sim 1.875^{\circ}$ latitude atmospheric grid) in our analyses. 
In this study, we focused on the SAT and $P$ change patterns of the transient and near-equilibrium responses, rather than the magnitude of change at any given location that depends on the radiative forcing and internal feedbacks (Rose et al. 2014; Rose and Rayborn 2016; Dai et al. 2020a). Thus, we will focus on the change patterns normalized by the global-mean warming rate (Santer et al. 1990; Tebaldi and Arblaster 2014), rather than the difference maps between a target period and a reference. The SAT and $P$ change patterns averaged over a 50-yr period from the CESM1.2.1 runs and three multi-millennium simulations, and over a $30-\mathrm{yr}$ period from the CMIP5 multimodel ensemble mean are normalized to local changes per $1 \mathrm{~K}$ of global warming (referred to as the normalized SAT and $P$ changes), and then are used to quantify the spatial features of the externally forced changes. Tests (by comparing change maps averaged over $30,50,75$, and 100 years) showed that averaging over a period 50 years of the CESM1.2.1 and multi-millennium simulations yielded stable change patterns that are likely to represent mostly forced response, although using 100-yr averages increases the change pattern correlations noticeably for precipitation as pointed out below. Since the CMIP5 ensemble mean contains much smaller internal variations than individual model runs, we used its 30-yr averages to represent the forced change patterns from these models. The impact of internal variability on the estimated forced change has been examined previously (e.g., Dai and Bloecker 2019), which depends on the magnitude of the external forcing. In our CESM1.2.1 $2 \times \mathrm{CO}_{2}$ experiment, the 30-yr-averaged maps already show fairly stable change patterns; thus our 50-yr averages likely represent mostly the forced signal.

The pattern correlation coefficient between two maps is calculated as

$$
r(x, y)=\frac{\sum_{i}\left[w_{i}\left(x_{i}-\bar{x}\right)\left(y_{i}-\bar{y}\right)\right]}{\sqrt{\sum_{i}\left[w_{i}\left(x_{i}-\bar{x}\right)^{2}\right]} \sqrt{\sum_{i}\left[w_{i}\left(y_{i}-\bar{y}\right)^{2}\right]}},
$$

where $x_{i}$ and $y_{i}$ refer to the values at grid box $i$ from two maps $x$ and $y, w_{i}=\cos \left(\mathrm{lat}_{i}\right)$ with lat ${ }_{i}$ as the latitude at the center of the grid box $i$, and $\bar{x}$ and $\bar{y}$ are the global mean of $x$ and $y: \bar{x}=\sum_{i} w_{i} x_{i} / \sum_{i} w_{i}$ and $\bar{y}=\sum_{i} w_{i} y_{i} / \sum_{i} w_{i}$. The $\sum_{i}$ is for summation over all grid boxes.

We consider two maps $x$ and $y$ to be similar if their $r(x, y)$ value exceeds a threshold $r_{o}$. There are different ways to determine and justify a choice of $r_{o}$. For example, if one wants to have one of the maps to be able to explain or account for at least $50 \%$, two-thirds, or $90 \%$ of the (spatial) variance in the other map, then the $r_{o}$ should be, respectively, $0.71,0.82$, or 0.95 . If one wants to have one of the maps to have the same or similar values as in the other map over at least $50 \%$, two-thirds, or $90 \%$ of the global area, then the $r_{o}$ should be $0.54,0.66$, or 0.88 for SAT and $0.59,0.70$, or 0.90 for $P$, respectively, based on our following calculations. Here we chose $r_{o}=0.66$ for SAT and $r_{o}=0.70$ for $P$, which represents similarity (i.e., similar values) over at least two-thirds of the global area, as this makes more intuitive sense than an $r_{o}$ value that is based on the percentage variance explained. Thus, in this paper two change patterns are considered similar only if their values are identical or similar (i.e., $100 \%$ correlated) over at least two-thirds of the total area. Most of the pattern correlations examined here exceed 0.90 , which means that there exist identical or similar values between the two change patterns over at least $90 \%$ of the global area according to our estimated $r_{o}$ values.

To derive the $r_{o}$ value that represents similarity over a given percentage area, we take the change map for SAT (or for $P$ ) averaged for the last 50 years from the CESM1.2.1 abrupt $4 \times \mathrm{CO}_{2}$ simulation as the baseline map $x$. We then randomly select a subset of the grid boxes on map $x$ that add up to $50 \%$, one-third, or $10 \%$ of the global area and replace the SAT (or $P$ ) change values at those grid boxes using randomly selected values from the change map $(z)$ for the first 50 -yr period, with the same grid box location being excluded in each draw to prevent the value on $z$ at the same location being used because it could be similar to the value on $x$ at this location. This newly created map $(y)$ has the same value as $x$ for at least $50 \%$, two-thirds, or $90 \%$ of the global area; thus, we can interpret their $r(x, y)$ as representing similarity between $x$ and $y$ over at least $50 \%$, two-thirds, or $90 \%$ of the globe, respectively. To account for the sampling uncertainty and be conservative, we created $1000 y$ maps $\left(y_{i}, i=1, \ldots, 1000\right)$ and used the 95th percentile of the $r\left(x, y_{i}\right), i=1, \ldots, 1000$, as the threshold value $r_{o}$ for each of the percentage-area cases. Our calculations using the CESM1.2.1 $4 \times \mathrm{CO}_{2}$ simulation yielded an $r_{o}$ value of $0.54,0.66$, or 0.88 for the $50 \%$, twothirds, or $90 \%$ similarity cases, respectively, for SAT; and $0.59,0.70$, or 0.90 for the three similarity cases for precipitation change. The $r_{o}$ values are similar if the CESM1.2.1 $2 \times \mathrm{CO}_{2}$ simulation was used. These $r_{o}$ values can help the reader to interpret a given $r(x, y)$ in terms of the fraction of areas having similar or identical values. For example, for two SAT change maps with $r=$ 0.70 , these $r_{o}$ values suggest that identical or similar SAT changes exist over more than two-thirds but less than $90 \%$ of the areas on these maps. Please note that in model-simulated fields, the grid boxes with uncorrelated values may be clustered over certain regions, rather than randomly scattered around the world as in our tests. 


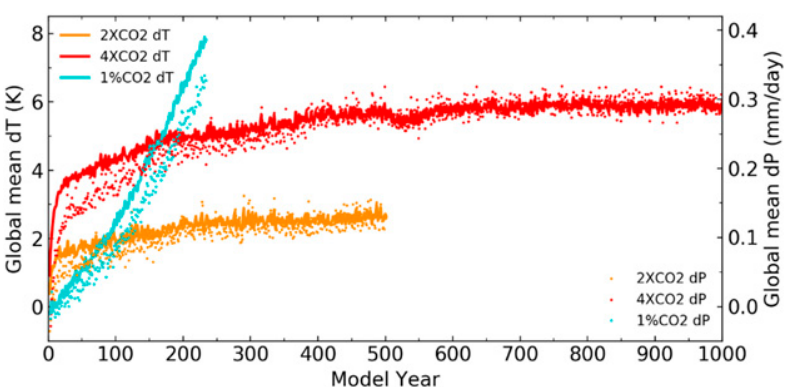

FIG. 1. Time series of the global-mean annual surface air temperature (lines; left $y$ axis) and precipitation (dots; right $y$ axis) changes (relative to the PiControl climatology) from the CESM1 $2 \times$ $\mathrm{CO}_{2}$ (orange), $4 \times \mathrm{CO}_{2}$ (red), and $1 \% \mathrm{CO}_{2}$ (blue) experiments.

Clearly, these two cases have different physical meaning, but their pattern correlation coefficients should be the same based on Eq. (1). Thus, their $r_{o}$ values should be the same as well. Here we did not attempt to distinguish those two cases.

\section{Results from the CESM1.2.1 simulations}

\section{a. Temperature change patterns}

We first examine the global-mean SAT and precipitation changes from the three CESM1.2.1 experiments (Fig. 1). Both the global-mean SAT and precipitation changes from the $2 \times \mathrm{CO}_{2}$ and $4 \times \mathrm{CO}_{2}$ experiments show gradual increases toward the equilibrium levels, while the $1 \% \mathrm{CO}_{2}$ experiment shows steady increases that appear to accelerate with time. For the global-mean SAT in the $1 \% \mathrm{CO}_{2}$ run, the transient response (relative to PiControl) around the time of the first $\mathrm{CO}_{2}$ doubling (around years 61-80) and the second doubling (around years $131-150$ ) is $\sim 1.64$ and $4.02 \mathrm{~K}$, respectively. In comparison, the near-equilibrium climate response in the $2 \times \mathrm{CO}_{2}$ (averaged over years 451-500) and $4 \times \mathrm{CO}_{2}$ (averaged over years 951-1000) simulations is $\sim 2.68$ and $5.91 \mathrm{~K}$, respectively. Although the global-mean SAT has not reached a complete equilibrium state by the end of the $2 \times \mathrm{CO}_{2}$ and $4 \times \mathrm{CO}_{2}$ experiments, most of the warming has already been realized (Dai et al. 2020a). Thus, we will use the SAT and $P$ change patterns near the end of these simulations to approximately represent the patterns of the equilibrium response, while the normalized change patterns during their early periods (especially during the first 100 years) and from the 1\% $\mathrm{CO}_{2}$ run will be used to represent the transient response patterns.

The normalized annual SAT changes (relative to PiControl) averaged over different 50-yr periods from the three CESM1.2.1 experiments are similar, as reflected by the small differences between the final and earlier 50-yr periods (Fig. 2). Figures 2a-c show the wellknown pattern (using the last 50 years of the experiments) with greater warming at northern high latitudes and over continents and lesser warming over the northern North Atlantic and Southern Oceans (Meehl et al. 2004; Collins et al. 2013). The enhanced warming at northern high latitudes, particularly over the Arctic region, is commonly referred to as Arctic amplification (AA; Serreze and Francis 2006; Screen and Simmonds 2010; Serreze and Barry 2011). AA is seen only in the cold season and mainly over areas with large sea ice loss in observations (Screen and Simmonds 2010; Dai et al. 2019) and in model simulations with increasing greenhouse gases (Holland and Bitz 2003; Collins et al. 2013; Barnes and Polvani 2015). It is likely caused primarily by sea ice loss (Screen and Simmonds 2010; Dai et al. 2019), which in turn is caused by surface warming due to increasing GHGs, water vapor and cloud feedbacks, and other processes (Pithan and Mauritsen 2014; Mortin et al. 2016). The reduced warming over the northern North Atlantic, most noticeable in the transient response (Fig. 2c), has been ascribed to changes in surface currents (Dai et al. 2005) and weakening of the Atlantic meridional overturning circulation (Ishizaki et al. 2012; Geoffroy and Saint-Martin 2014), and the weak warming over the Southern Ocean (again most noticeable during the early transient periods; Fig. 2) is due to the deep ocean mixed layers there (Tebaldi and Arblaster 2014). Over the tropical Pacific, enhanced warming is seen along the equatorial eastern and central Pacific (mainly after the first 100 years), with reduced warming to the north and south of it (Figs. 2a-c). Thus, this model shows a weak El Niño-like response. This response is also seen in the longterm simulations by CESM1.0.4 (not shown) and, to some degree, also by MPI-ESM-1.1 (Figs. 11a,c) and GISS-E2-R (not shown).

Figures $2 \mathrm{~d}-\mathrm{f}$ show some noticeable differences between the first and last 50-yr periods, with less warming per $1 \mathrm{~K}$ of global warming during the first 50 years over the Arctic, northern North Atlantic Ocean, and parts of the Southern Ocean, but more warming over most continents (especially over central North America and Asia) and the western and central North Pacific. However, these differences are small $\left(\sim 0.1-0.3 \mathrm{~K} \mathrm{~K}^{-1}\right)$ compared with the warming $\left(\sim 3 \mathrm{~K} \mathrm{~K}^{-1}\right.$ at northern high latitudes and $1-2 \mathrm{~K} \mathrm{~K}^{-1}$ over most land; Figs. 2a-c), except for the northern North Atlantic and a few other areas, where the differences can reach 1-2 K (Figs. 2d-f). Most of these differences occur during the first 100 years (Figs. 2j-1); whereas for other subsequent periods, the differences with the last 50 years are very small (within $\pm 0.2 \mathrm{~K} \mathrm{~K}^{-1}$ ) over most of the globe (Figs. $2 \mathrm{~g}$-i). The smaller warming during the first 50 years over the Arctic and Southern Ocean is seen mostly in the cold season 
(a) Normalized dT, 2XCO2, Year 451-500 mean
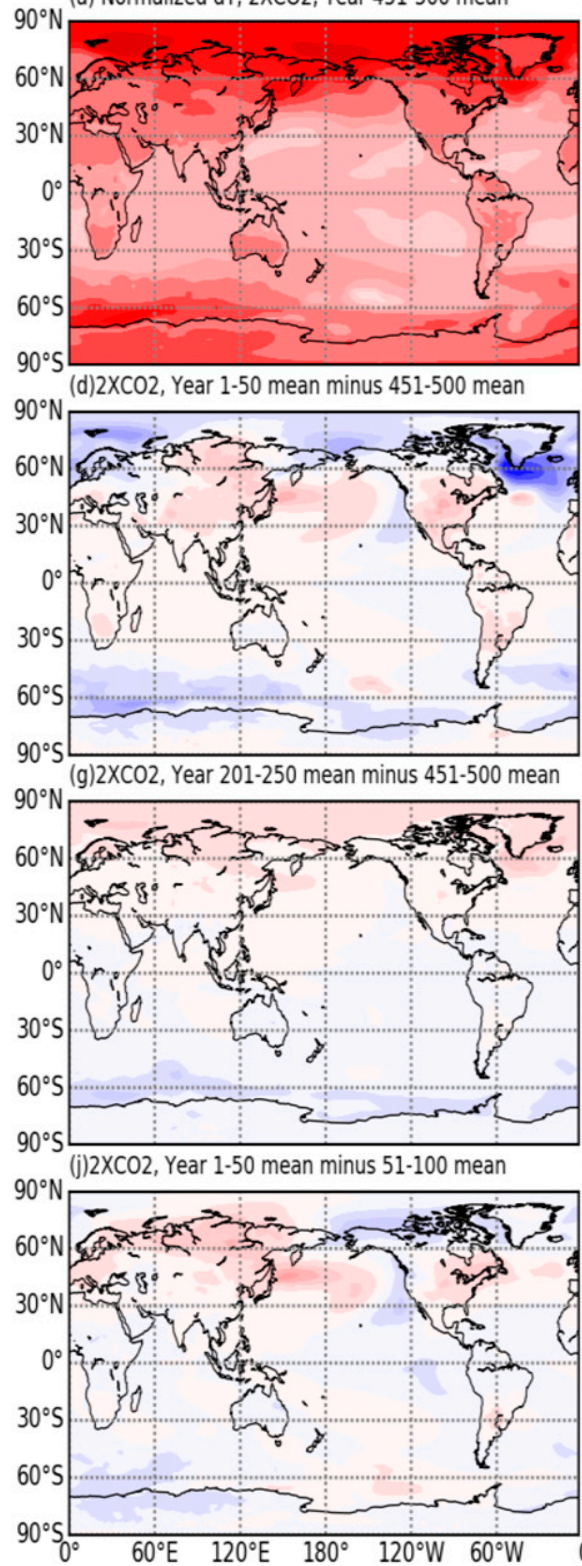

(b) Normalized dT, 4XCO2, Year 951-1000 mean

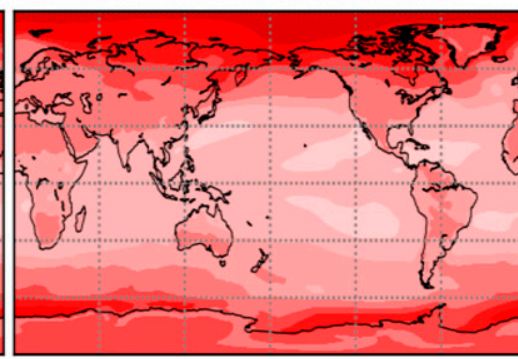

(e)4XC02, Year 1-50 mean minus 951-1000 mean

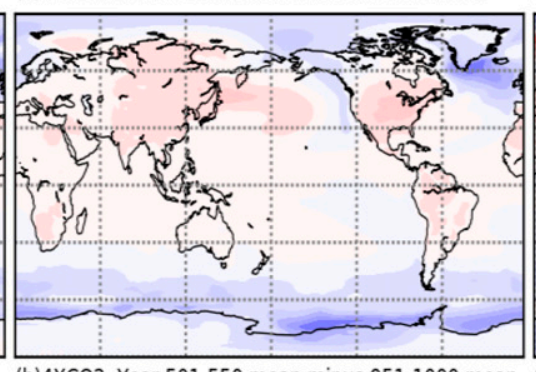

(h) 4 XCO2 Year 501-550 mean minus 951-1000 mean (i)

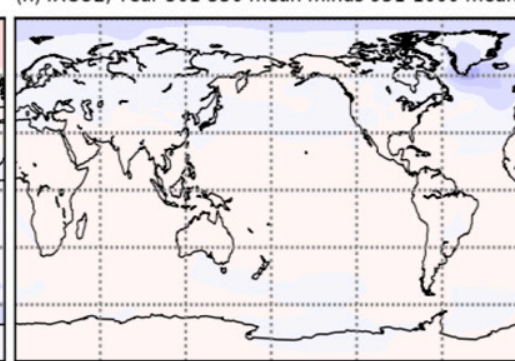

(k)4XCO2, Year 1-50 mean minus 51-100 mean

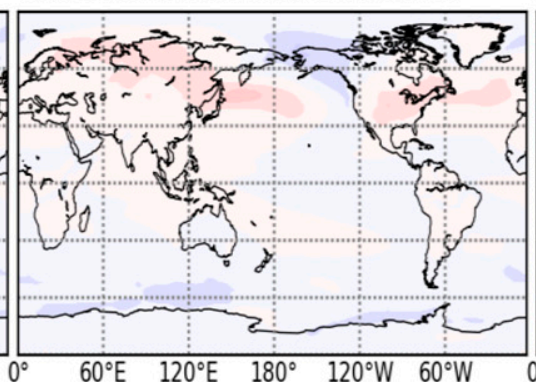

(c) Normalized dT, 1\%CO2, Year 151-200 mean

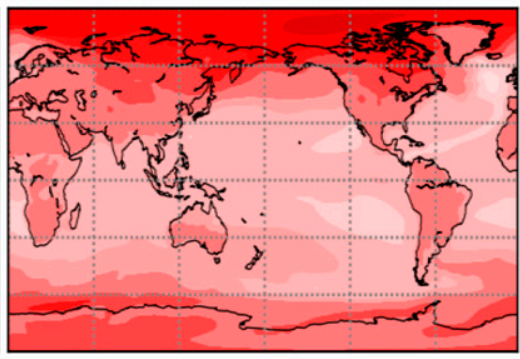

(f) $1 \% C 02$, Year 1-50 mean minus 151-200 mean

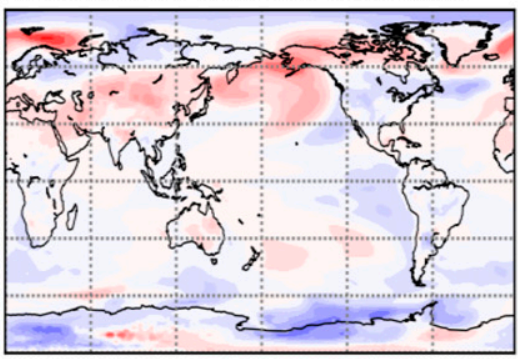

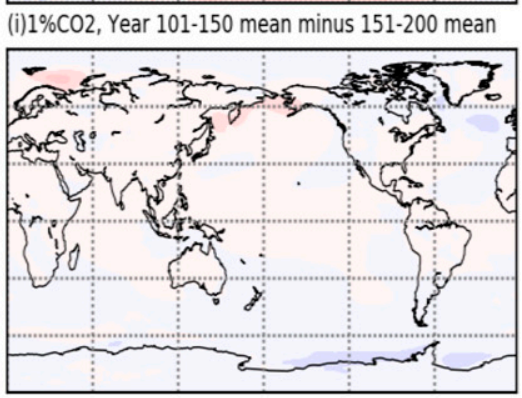

(I) $1 \% C 02$, Year 1-50 mean minus 51-100 mean
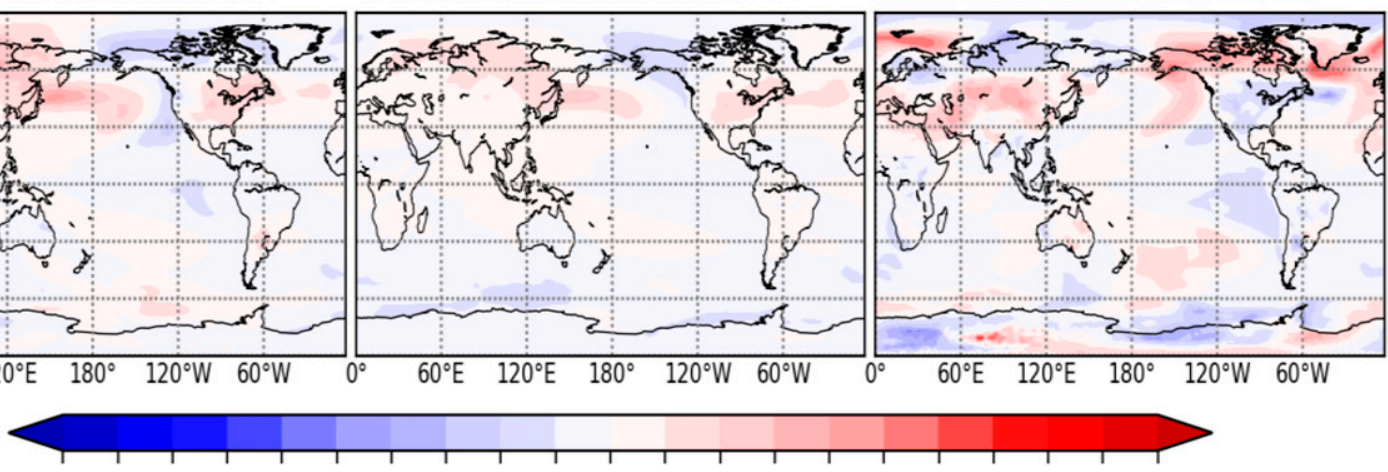

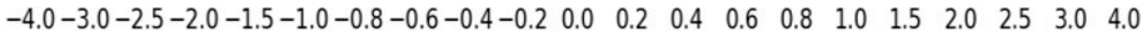

FIG. 2. Normalized annual surface air temperature change patterns (as the ratio of local vs global-mean changes, in units of K per $1 \mathrm{~K}$ of global warming) from the CESM1.2.1 $2 \times \mathrm{CO}_{2}, 4 \times \mathrm{CO}_{2}$, and $1 \% \mathrm{CO}_{2}$ experiments averaged over years (a) 451-500, (b) 951-1000, and (c) 151-200, and the differences between years (d) $1-50$ and 451-500, (g) 201-250 and 451-500, and (j) 1-50 and 51-100 from the $2 \times \mathrm{CO}_{2}$ experiment; between years (e) 1-50 and 951-1000, (h) 501-550 and 951-1000, and (k) 1-50 and 51-100 from the $4 \times \mathrm{CO}_{2}$ experiment; and between year (f) 1-50 and 151-200, (i) 101-150 and 151-200, and (1) 1-50 and 51-100 from the $1 \% \mathrm{CO}_{2}$ experiment. All the changes are relative to the PiControl run climatology.

while the larger warming over continents and smaller warming over the northern North Atlantic during the first 50 years are seen in all seasons (figures not shown). Thus, GHG-induced warming initially is slightly stronger over land but weaker over the Arctic, northern
North Atlantic Ocean and parts of the Southern Ocean than later periods, but after the first 50 years or so the warming patterns do not change noticeably over time and are comparable to the final, near-equilibrium pattern under both the $2 \times \mathrm{CO}_{2}$ and $4 \times \mathrm{CO}_{2}$ increases 
in the CESM1.2.1. As shown, below, the initial warming over the Arctic is actually stronger than the later periods in the CMIP5 ensemble mean, MPI-ESM-1.1 and GISSE2-R models.

Figure 3 shows the zonal-mean normalized SAT changes over the first, middle, and last 50 -yr periods from the CESM1.2.1 simulations. Consistent with Figs. 2d-i, relatively large differences are seen over the northern high latitudes and the Southern Ocean latitudes during the winter and annual mean, presumably related to different sea ice melting over different warming periods (Dai et al. 2019), while the differences are small over the low and middle latitudes $\left(\sim 50^{\circ} \mathrm{S}-50^{\circ} \mathrm{N}\right)$ and for the summer-season high latitudes, when the impact of sea ice melting on SAT is small (Dai et al. 2019).

The consistency of the warming patterns is supported by the strong pattern correlation coefficients from 0.80 to 0.99 between the last and earlier 50 -yr time periods over the globe (Fig. 4a). The pattern correlation coefficients increase noticeably during the first 200 years, during which land shows higher consistency than ocean, presumably due to the quicker response time of land. Thereafter, the correlations stay nearly constant and close to one, suggesting that the normalized SAT change patterns vary little over time after the first $\sim 200$ years and among the different experiments. This is also true for the seasonal change patterns over the globe, with slightly higher (lower) similarity in boreal autumn (summer); figures not shown. The correlations for different latitude bands and for land and ocean show that the temporal consistency is stronger for the change patterns over land than over ocean (Figs. 4b-e). The pattern consistency is considerably lower for the four latitude zones than for the globe as a whole during the first 200 years. This is likely due to the fact that the global-scale change patterns (e.g., high-latitude vs lowlatitude differences) persist over time and contribute greatly to the correlations shown in Fig. 4a, while the correlations for the individual latitude zones depend more on local and regional patterns that may evolve considerably during the first 200 years, partly due to internal variability.

The above results suggest that the annual and seasonal warming patterns in response to increased $\mathrm{CO}_{2}$ are very similar (i.e., having similar or identical values over at least $90 \%$ of the areas) after the initial 100-200 years regardless of the forcing scenarios. Furthermore, even the transient warming patterns in the $1 \% \mathrm{CO}_{2}$ experiment is similar to the near-equilibrium warming pattern revealed by the $2 \times \mathrm{CO}_{2}$ and $4 \times \mathrm{CO}_{2}$ experiments. During the first 200 years, the global-mean SAT change in the $2 \times \mathrm{CO}_{2}$ and $4 \times \mathrm{CO}_{2}$ experiments reached $\sim 2.2$ and $4.7 \mathrm{~K}$, respectively (Fig. 1), accounting for $\sim 80 \%$ of the total near-equilibrium warming.

\section{b. Precipitation change patterns}

Similar to the SAT case, the patterns of the normalized annual precipitation changes (relative to PiControl) from the three CESM1.2.1 experiments looked similar over different 50 -yr periods, even for the averages over years 1-50 (to a lesser degree for the $1 \% \mathrm{CO}_{2}$ case; not shown), as reflected by the small differences between the final and earlier 50-yr periods over most of the globe (Fig. 5, except for years $1-50$ in the $1 \% \mathrm{CO}_{2}$ experiment). As is well documented (e.g., Collins et al. 2013; Dai et al. 2018), precipitation increases over most of the globe, except parts of the tropics and subtropics mainly over the eastern tropical Pacific, Atlantic, and Indian Oceans, where it decreases (Figs. 5a-c). Increased water vapor leads to increased moisture convergence and thus more precipitation during a rain event in a warmer climate (Trenberth et al. 2003; Dai et al. 2020b). In the tropics, increased low-level specific humidity leads to more positive buoyancy (Chen et al. 2020), which causes more intense moist convection and contributes to increased precipitation there, although the decreased number of convective events (Sun et al. 2007; Dai et al. 2018) and the associated weakening in the mean upward motion (Held and Soden 2006) partly offset the precipitation increase there. The subtropical precipitation decline is a robust large-scale feature in the current and previous model projections (Scheff and Frierson 2012a,b; He and Soden 2016; Dai et al. 2018), and it persists in both the transient and equilibrium responses. We will examine its causes further in another study.

Figures $5 \mathrm{~d}-\mathrm{f}$ show some noticeable differences between the first and last 50-yr periods, particularly for the tropics in the $1 \% \mathrm{CO}_{2}$ experiment (Fig. 5f). Precipitation increases less per $1 \mathrm{~K}$ of global warming during the first 50 years than during subsequent and the last 50 -yr periods over most of the tropical Pacific, whereas it is the opposite over most of the western Pacific Ocean (Figs. 5d-f). These difference patterns are broadly similar among the four seasons (figure not shown). Similar to the SAT case, most of these differences occur during the first 100 years (Figs. 5j-1), whereas for other subsequent periods the differences with the last 50 years are very small (within $\pm 0.1 \mathrm{~mm} \mathrm{day}^{-1}$ ) over most of the globe (Figs. $5 \mathrm{~g}$-i). This suggests that the precipitation change patterns do not vary noticeably over time after year 100 and are comparable to the final, near-equilibrium pattern under both the $2 \times \mathrm{CO}_{2}$ and $4 \times \mathrm{CO}_{2}$ increases in the CESM1.2.1. On the other hand, the $P$ change patterns at low latitudes during years $1-50$ in the $1 \% \mathrm{CO}_{2}$ experiment can differ substantially from latter periods (Figs. 5f,l), likely due to 

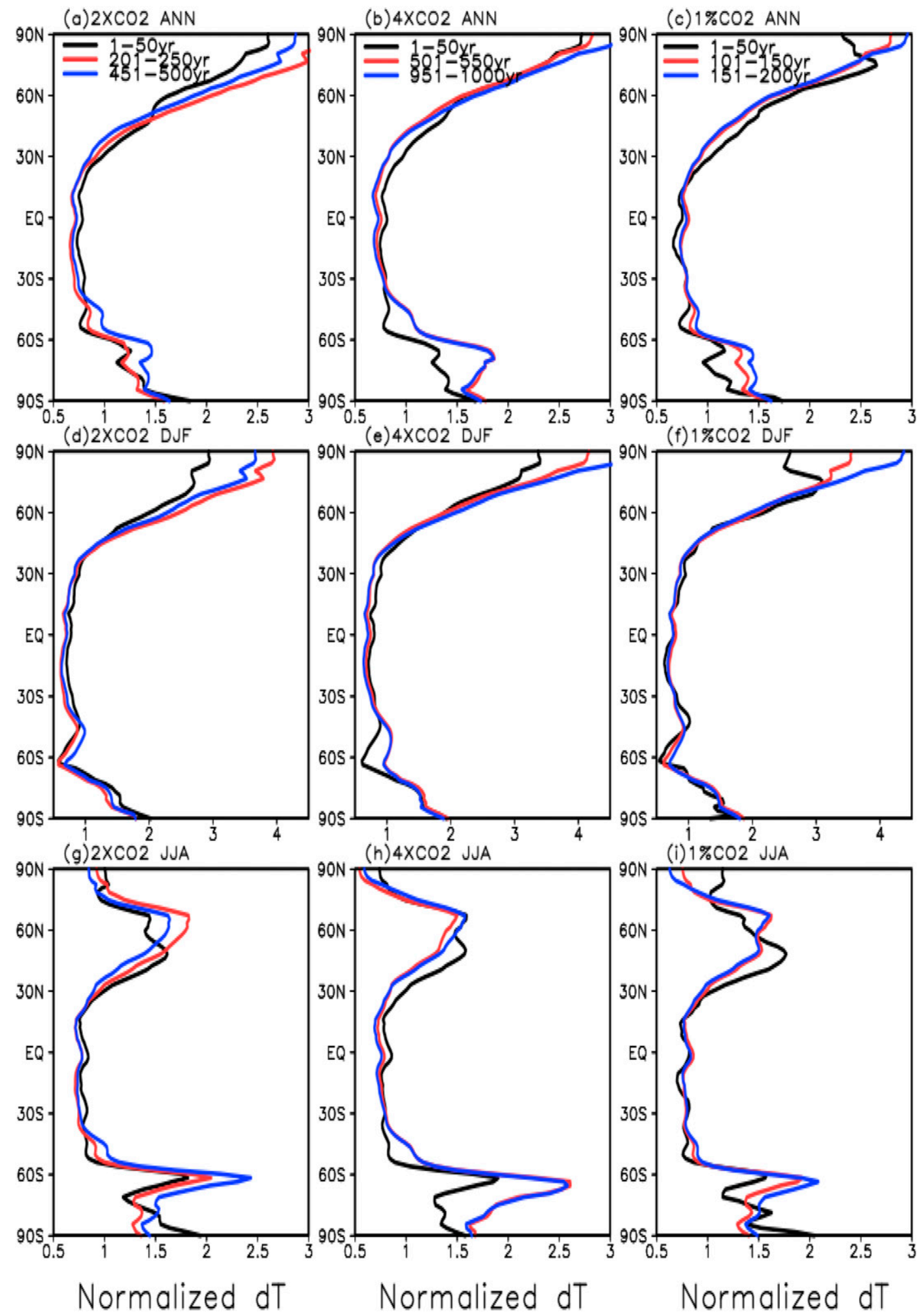

Normalized dT

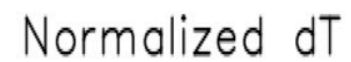

FIG. 3. Zonal-mean normalized (a)-(c) annual, (d)-(f) DJF, and (g)-(i) JJA temperature changes (in mm day ${ }^{-1}$ per $1 \mathrm{~K}$ of global warming) from the CESM1 (a),(d),(g) $2 \times \mathrm{CO}_{2}$, (b),(e),(h) $4 \times \mathrm{CO}_{2}$, and (c),(f),(i) $1 \% \mathrm{CO}_{2}$ experiments during the first, middle, and last 50-yr periods. 

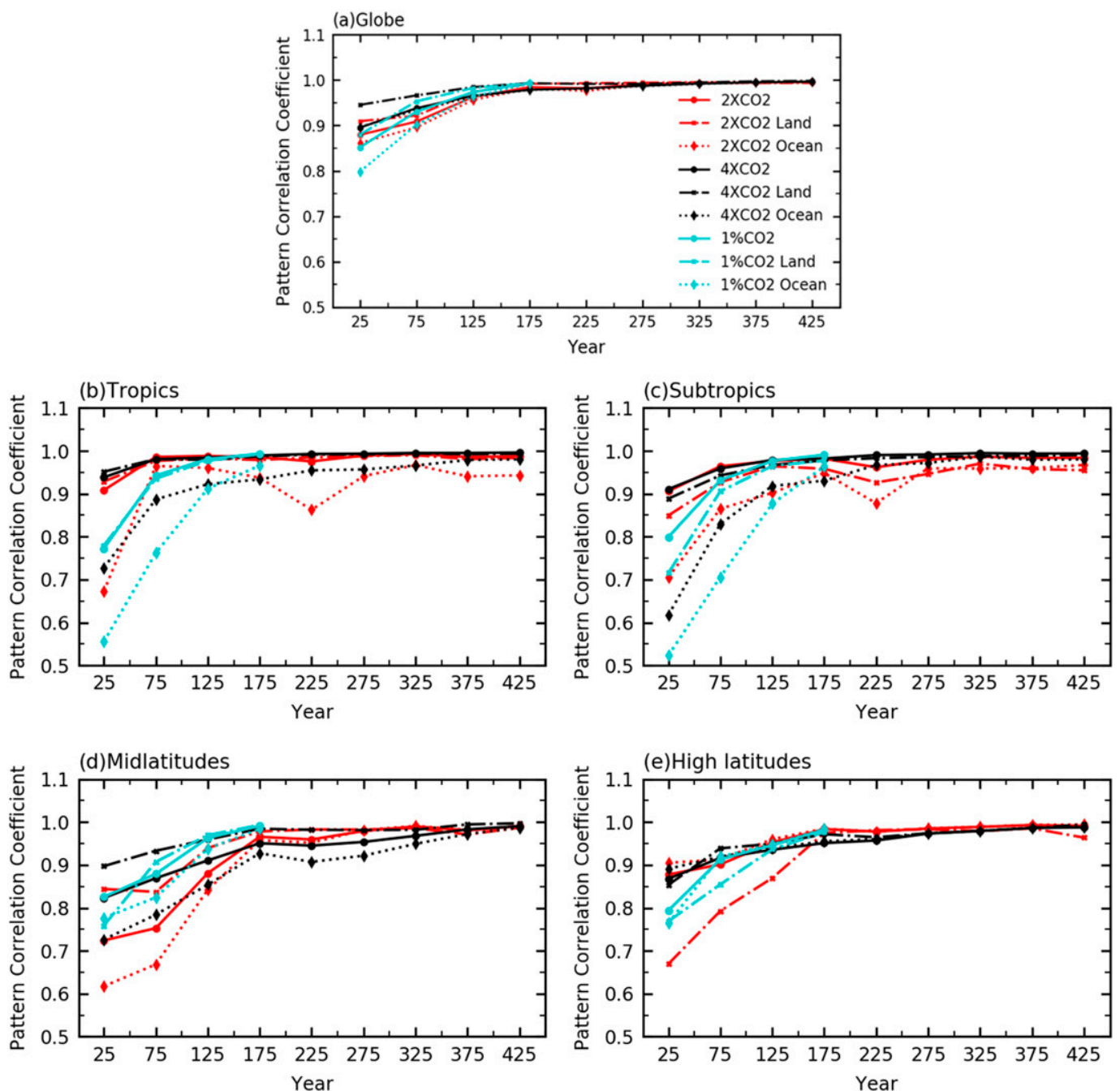

FIG. 4. Temporal variations in the pattern correlation coefficients $(r)$ of the 50-yr-averaged, normalized annual surface air temperature change between the last 50 years and a 50-yr period centered at the plotted year on the $x$ axis for the (a) globe, (b) tropics $\left(20^{\circ} \mathrm{S}-20^{\circ} \mathrm{N}\right)$, (c) subtropics $\left(40^{\circ}-20^{\circ} \mathrm{S}\right.$ and $\left.20^{\circ}-40^{\circ} \mathrm{N}\right)$, (d) midlatitudes $\left(60^{\circ}-40^{\circ} \mathrm{S}\right.$ and $\left.40^{\circ}-60^{\circ} \mathrm{N}\right)$, and (e) high latitudes $\left(90^{\circ}-60^{\circ} \mathrm{S}\right.$ and $\left.60^{\circ}-90^{\circ} \mathrm{N}\right)$ in the three CESM1 experiments. The land and ocean have also been separated and indicated by dashed lines. The $r$ values do not change much after year 450 . Correlation coefficients above $\sim 0.88$ indicate that at least $90 \%$ of the grid boxes have similar or identical temperature changes.

large influences of $P$ internal variability during years $1-50$ when the $\mathrm{CO}_{2}$ forcing is comparatively small.

The zonal-mean precipitation changes over the first, middle, and last 50-yr periods are shown in Fig. 6. Positive $P$ changes are seen over the middle and high latitudes and tropics across all the experiments, and they persist to the end of the simulations. Decreasing $P$ is seen over $15^{\circ}-25^{\circ} \mathrm{N}$ and $10^{\circ}-20^{\circ} \mathrm{S}$ (Figs. 5a-c) across all the experiments and it generally persists to the end of the simulations, although some exceptions are evident (e.g., the red line in Fig. 6 a over $15^{\circ}-25^{\circ} \mathrm{N}$ is positive while the black line in Fig. $6 \mathrm{c}$ shows negative $P$ changes over $\left.20^{\circ}-35^{\circ} \mathrm{N}\right)$. Noticeable differences in Arctic and tropical $P$ changes are seen during DJF (Figs. 6d-f), while the differences are small during JJA (Figs. $6 \mathrm{~g}-\mathrm{i}$ ).

Consistent with Figs. $5 \mathrm{f}$ and 7 shows that the $P$ changepattern correlations are low during the first 100 years of the $1 \% \mathrm{CO}_{2}$ experiment, as the $\mathrm{CO}_{2}$ forcing and thus the response is still relatively weak. This allows the random internal variations to have a major impact on the $P$ change patterns, especially during the first 50 years. However, for the $2 \times \mathrm{CO}_{2}$ and $4 \times \mathrm{CO}_{2}$ simulations, all the correlations indicate that at least over $90 \%$ of the areas have similar $P$ changes after the first 50 years over 
(a) Normalized dP, 2XC02, Year 451-500 mean

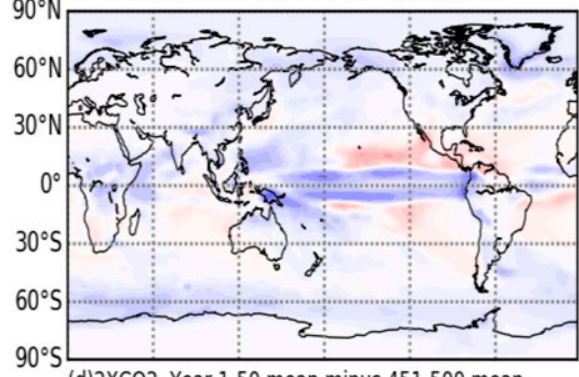

(d)2XC02, Year 1-50 mean minus 451-500 mean

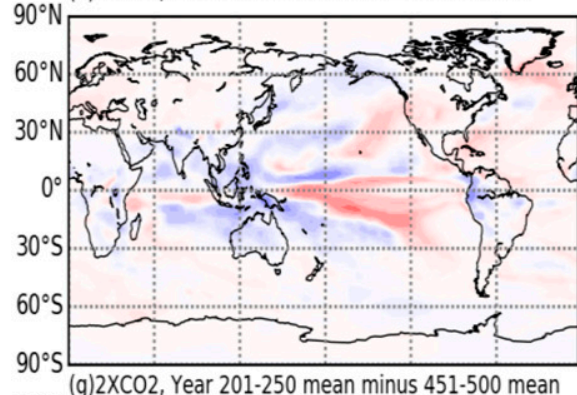

(g)2XC02, Year 201-250 mean minus 451-500 mean
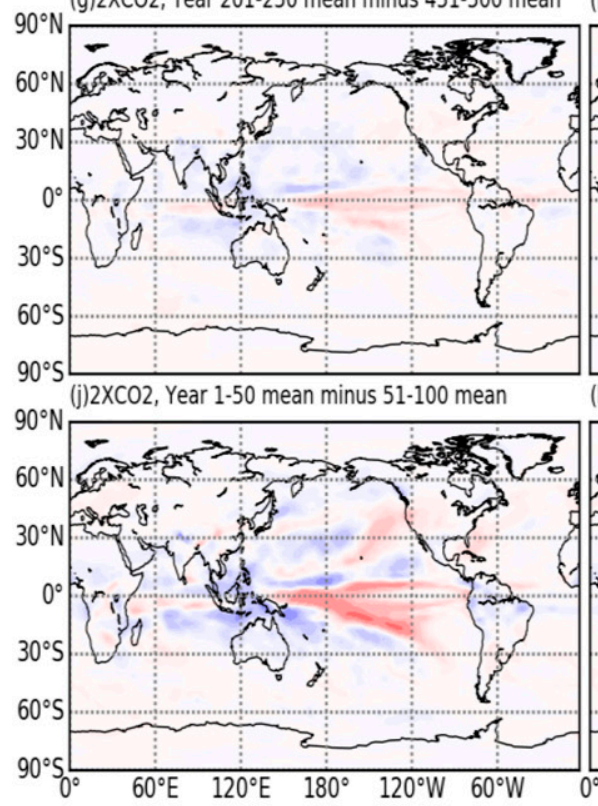

(b) Normalized dP, 4XCO2, Year 951-1000 mean

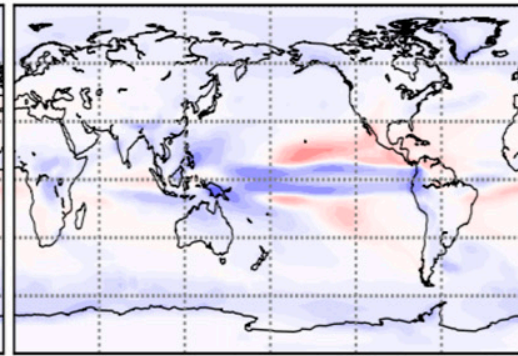

(e) 4XC02, Year 1-50 mean minus 951-1000 mean

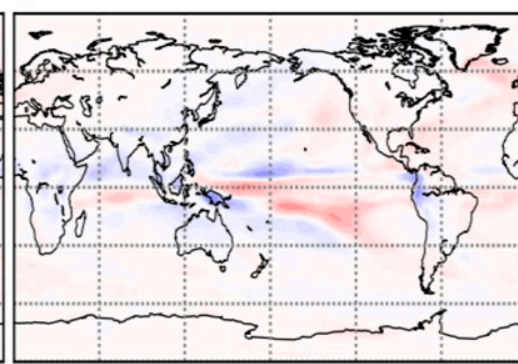

(h) 4XC02, Year 501-550 mean minus 951-1000 mean

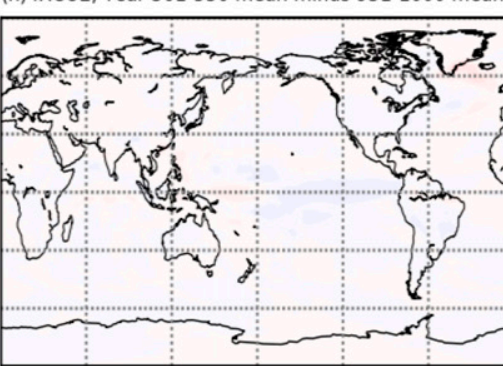

(k) $4 \times C 02$, Year 1-50 mean minus 51-100 mean

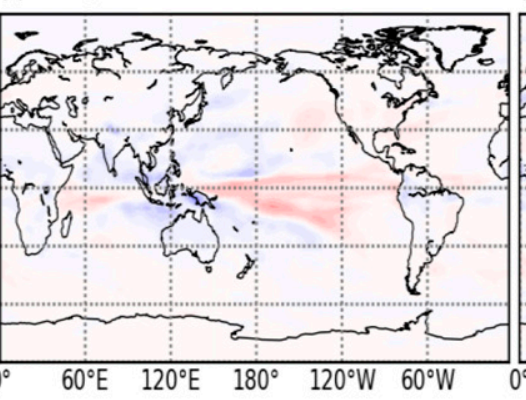

(c) Normalized dP, $1 \% \mathrm{CO}$, Year $151-200$ mean

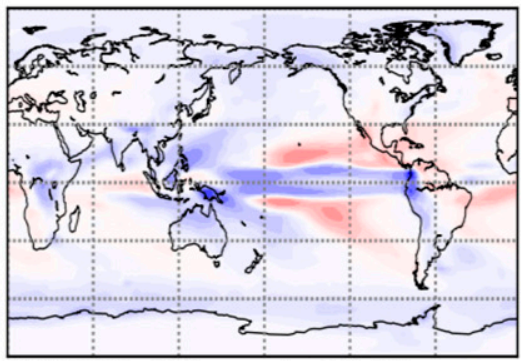

(f) $1 \% \mathrm{CO}$, Year 1-50 mean minus 151-200 mean

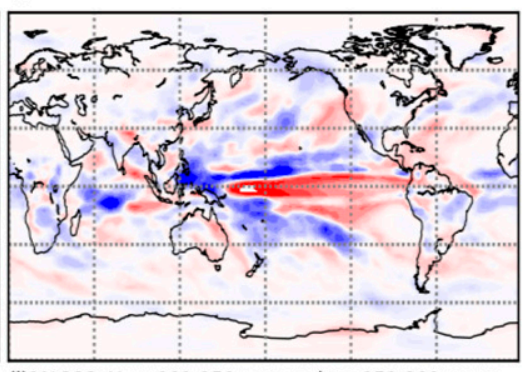

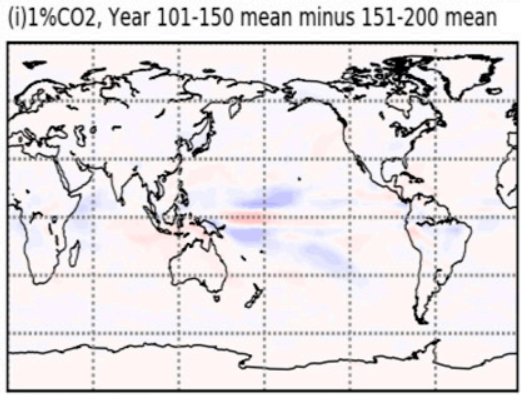

(I) $1 \% \mathrm{CO2}$, Year 1-50 mean minus 51-100 mean
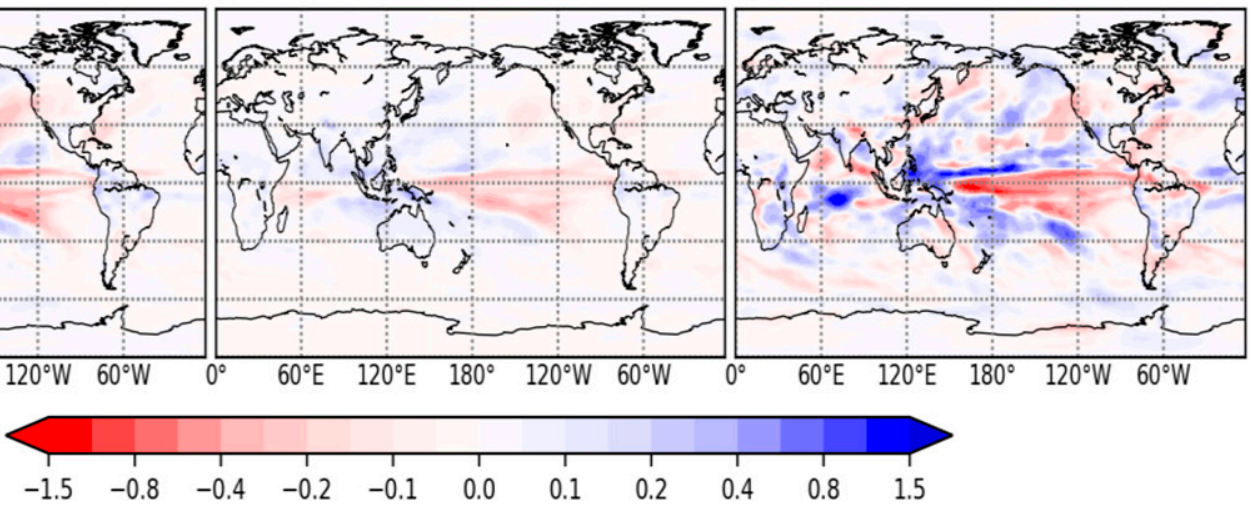

FIG. 5. As in Fig. 2, but for the normalized annual precipitation change patterns (color shading, in mm day ${ }^{-1}$ per $1 \mathrm{~K}$ of global warming). Results using 100-yr averages are similar.

the globe and the four latitude zones, while during the first 50 years only about two-thirds of the areas may have $P$ changes similar to the last 50-yr period (Fig. 7). Again, the $P$ change patterns during the early transient period of the first 200 years are closer to the final nearequilibrium pattern over land than over ocean, but thereafter all the correlations are close to one and thus the normalized $P$ change patterns vary little for both experiments (Fig. 7). This is also true for the seasonal $P$ changes, which show relatively high similarity in the boreal summer (figures not shown). These results suggest that the annual and seasonal $P$ change patterns in response to increased $\mathrm{CO}_{2}$ are similar, especially after the initial 100 years, although the $P$ change patterns may 


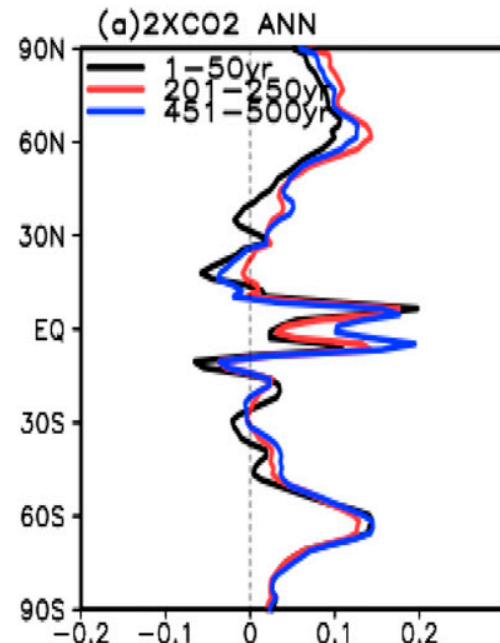

(b) $4 \times C O 2$ ANN
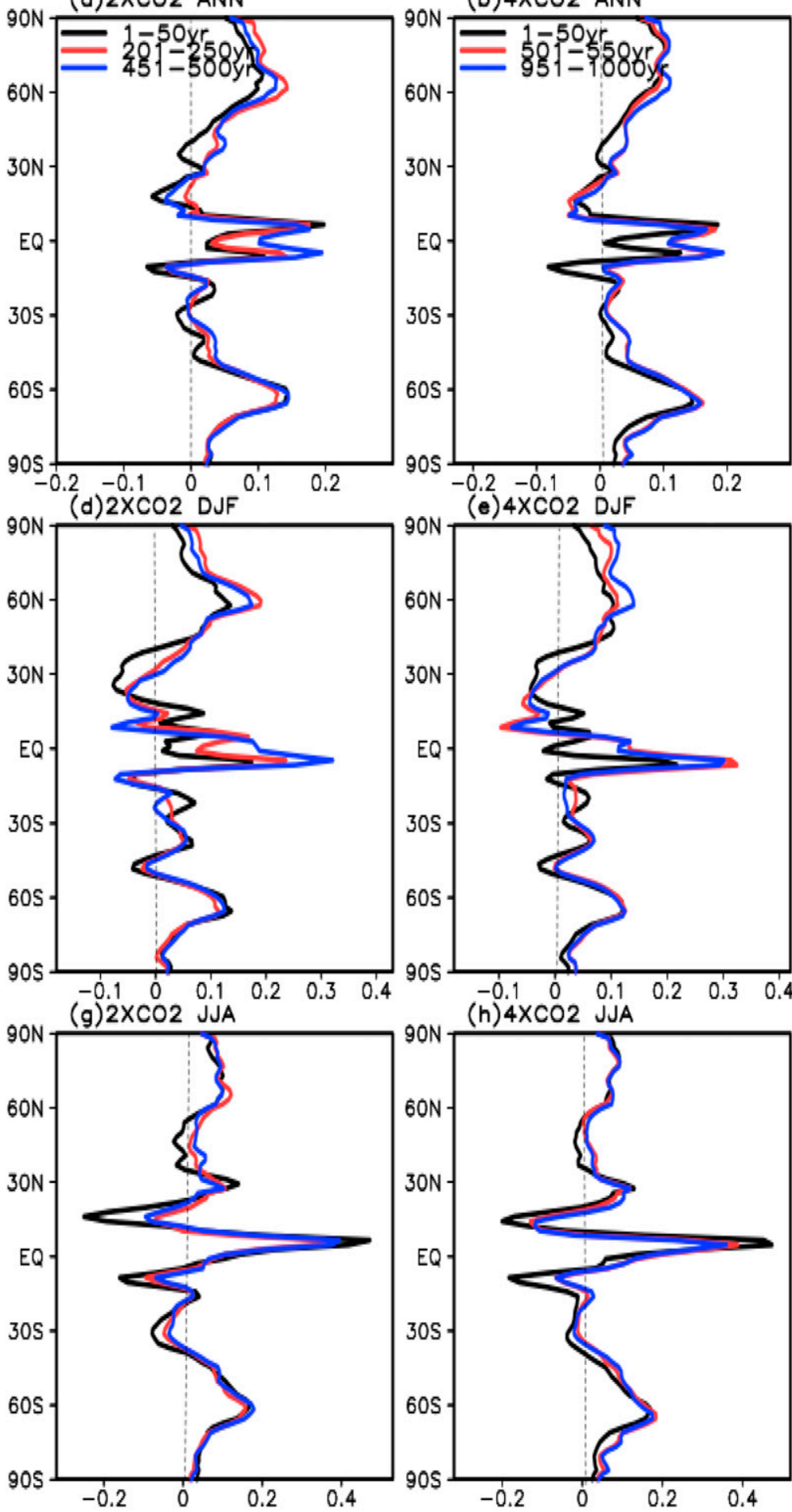

Normalized dP
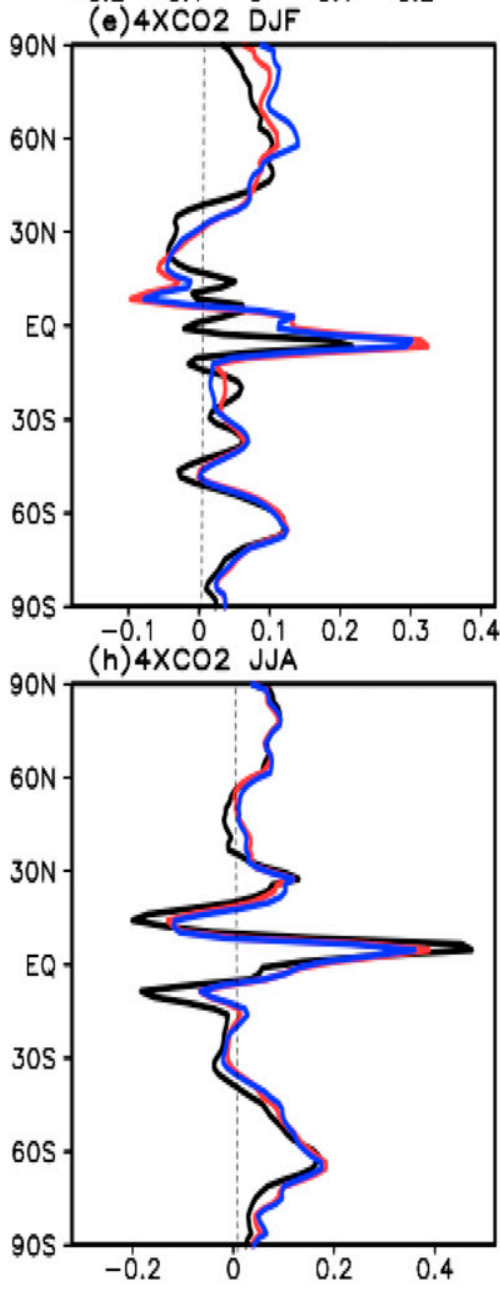

Normalized dP
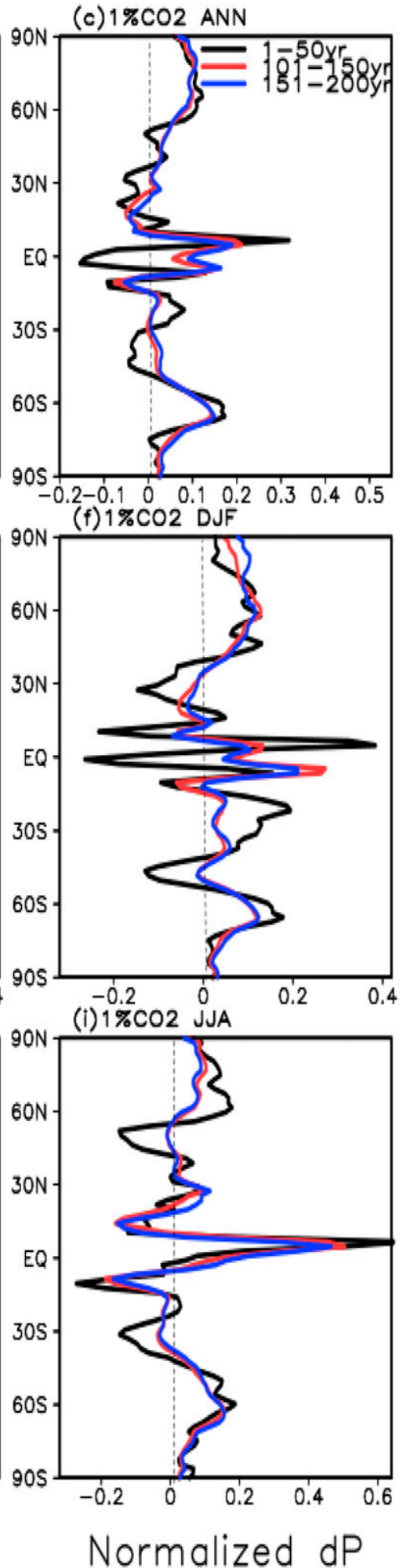

FIG. 6. Zonal-mean normalized (a)-(c) annual, (d)-(f) DJF, and (g)-(i) JJA precipitation changes (in mm day ${ }^{-1}$ per $1 \mathrm{~K}$ of global warming) from the CESM1 (a),(d),(g) $2 \times \mathrm{CO}_{2}$, (b),(e),(h) $4 \times \mathrm{CO}_{2}$, and (c),(f),(i) $1 \% \mathrm{CO}_{2}$ experiments during the first, middle, and last 50 -yr periods. The black dotted line is the zero line. 

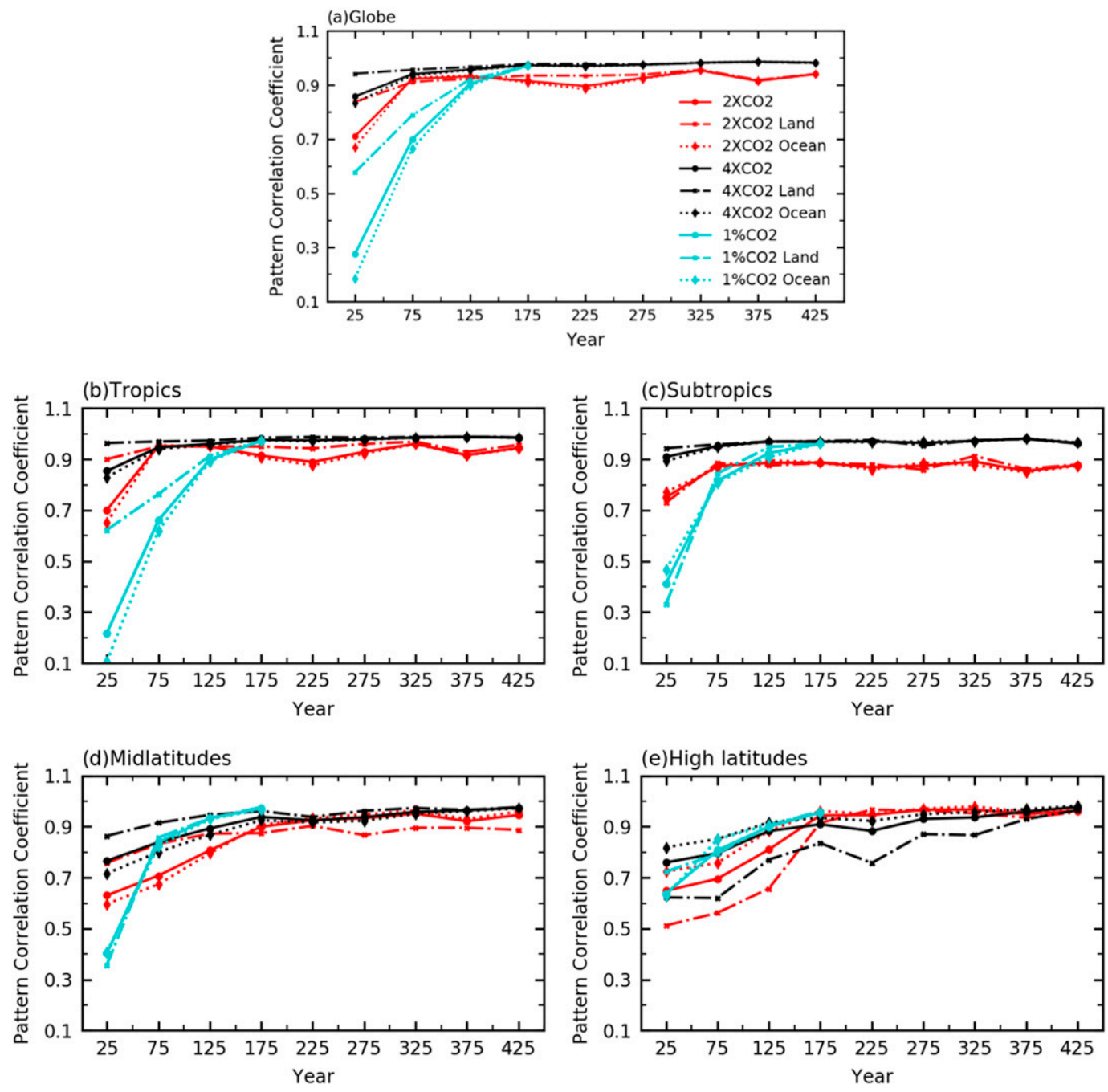

FIG. 7. As in Fig. 4, but for temporal variations in pattern correlation coefficients of the normalized annual precipitation changes. The correlations increase to above 0.7 for the $1 \% \mathrm{CO}_{2}$ case if 100 -yr (instead of 50 -yr) averages are used. Correlation coefficients above $\sim 0.90$ indicate that at least $90 \%$ of the grid boxes have similar or identical precipitation changes.

be heavily influenced by internal variability during the first 100 years in the $1 \% \mathrm{CO}_{2}$ experiment. This latter point differs from the SAT response, which shows similar change patterns even during the first 100 years of the $1 \% \mathrm{CO}_{2}$ experiment (Figs. 2 and 4 ).

We have also calculated and examined the pattern correlations between two adjacent 50 -yr periods, instead of between the last and an earlier 50 -yr periods as shown in Figs. 4 and 7. The results (figures not shown) are similar and they confirm that the pattern correlation coefficients of the normalized SAT and $P$ changes increase during the first few hundred years (and they are slightly higher than those shown in Figs. 4 and 7 during these early years) and then stabilize and are close to one thereafter. Additionally, we also compared the normalized SAT and $P$ change patterns between two different experiments for the same time period (Fig. 8). Besides the relatively low correlations for $P$ of the first 50 years between the $1 \% \mathrm{CO}_{2}$ and $2 \times \mathrm{CO}_{2}$ or $4 \times \mathrm{CO}_{2}$ experiments, strong consistency is shown for all the time periods and across the experiments, especially between the $2 \times \mathrm{CO}_{2}$ and $4 \times \mathrm{CO}_{2}$ experiments. In the $1 \% \mathrm{CO}_{2}$ experiment, the forced signal is still relatively weak during the first 50 years, when the precipitation change is heavily influenced by realization-dependent internal variations, leading to the lower correlations during this period.

Thus, the CESM1.2.1 simulations show that normalized SAT and $P$ change patterns remain approximately 

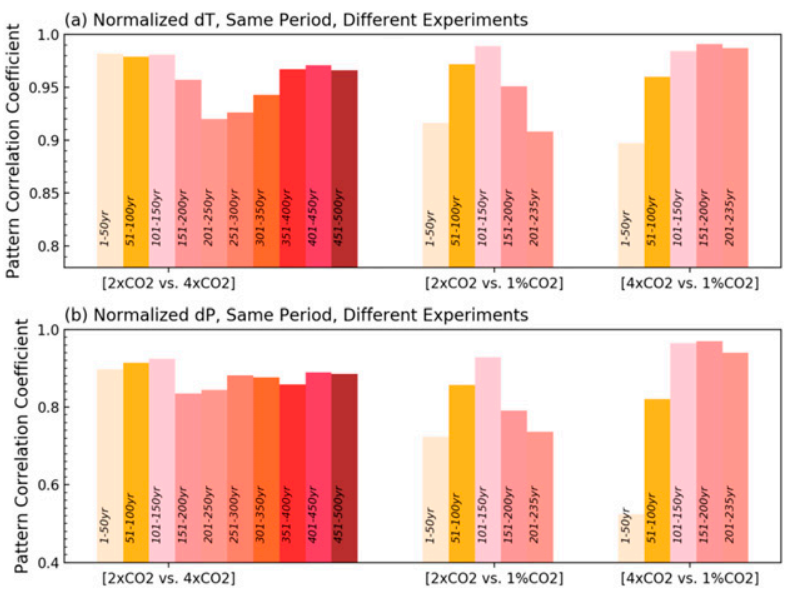

FIG. 8. Pattern correlation coefficients of the normalized annual (a) surface air temperature and (b) precipitation changes over the globe between the different experiments in the same period. The specific time periods and experiments are listed in each bar and along the $x$ axis, respectively. When 100-yr (instead of 50-yr) averages are used, the correlations in (b) increase to close to or above 0.9 for all cases except for the $1-100$-yr bar of the $4 \times \mathrm{CO}_{2}$ vs $1 \% \mathrm{CO}_{2}$, which increases to about 0.78 , while the changes for (a) are small.

the same over time and are independent of the forcing scenarios, especially after the first 50 years.

\section{Results from the CMIP5 extended simulations}

To find out whether the CESM1.2.1-based conclusion holds for other models, we repeated the above analyses for changes (relative to the 1970-99 mean from the historical runs) in the multimodel ensemble mean of the extended RCP8.5 simulation from nine CMIP5 models (Table 1). The use of multimodel ensemble mean allows us to smooth out most of the internal variations by averaging over a relatively short 30 -yr period. Both the globalmean SAT and $P$ increase steadily from 2005 to around 2200 and thereafter they increase slowly and stabilize near 2300 (figure not shown). Thus, the change patterns near the end of this simulation may be considered as an estimate of the equilibrium response pattern, while the earlier change patterns represent the transient response.

Similar to the CESM1.2.1 case, we compared the normalized SAT and $P$ change patterns averaged over different 30-yr time periods, and in Fig. 9 we show the change patterns for the last 30 -yr period and the differences between this and three earlier periods. Some noticeable SAT (Fig. 9c) and $P$ (Fig. 9d) differences are found between the period of 1971-2000 and last 30-yr period. The pattern correlations are 0.53 and 0.03 among the SAT and $P$ change maps, respectively. For other subsequent periods, the SAT change patterns are similar to those from the CESM1.2.1 (Figs. 2a-c, pattern correlations coefficients of 0.79-0.89) and they vary little over time, except for slightly stronger warming over the Arctic and weaker warming in the northern North Atlantic and the southern mid- to high latitudes during 2071-2100 (Fig. 9e). The $P$ change patterns (Fig. 9f) also are broadly comparable to the CESM1.2.1 case (Figs. 5a-c; pattern correlations of 0.56-0.61), with drying over many subtropical areas and wetting elsewhere, although the drying areas differ somewhat from those in Figs. 5a-c. The normalized $P$ response per $1 \mathrm{~K}$ of global warming is slightly weaker and different during the earlier periods than those during 2271-2300 over most of the globe (Figs. 9f,h). This may be partly due to the smaller warming rate during the later periods as the global warming rate is the denominator in this ratio. For the subsequent periods, there exist strong pattern correlations $(r=0.90-0.99)$ among these change maps over different periods (Fig. 9).

\section{Results from the abrupt $4 \times \mathrm{CO}_{2}$ multi- millennium simulations}

Three abrupt $4 \times \mathrm{CO}_{2}$ multi-millennium simulations are further analyzed to understand the transient and equilibrium response. Both the global-mean SAT and $P$ in these multi-millennium simulations increase rapidly during the first 400 years and then rise steadily until about year 1000; thereafter they increase slowly and stabilize after about year 2500 (Fig. 10). Thus, the change patterns near the end of this simulation may be considered as a fairly accurate estimate of the equilibrium response pattern, while the change patterns before year 1000 represent the transient response.

We examined the normalized SAT and $P$ change patterns over different time periods from the multimillennium simulations, and they are broadly comparable. Figure 11 shows the normalized SAT and $P$ change patterns for a transient period (year 301-350, which is around the middle of the main transient period; Fig. 10) and the last 50 years together with their difference from the MPI-ESM-1.1 (results for the other two models are similar and not shown). The normalized SAT and $P$ change patterns are similar between the two time periods and among the three models, with strong pattern correlation coefficients around 0.80 for SAT among them (except CESM1.0.4 vs GISS-E2-R for the year 301-350 case; Fig. 12a). The $P$ change pattern correlations among the models are substantially lower, especially with the GISS-E2-R (Fig. 12b). This suggests that the $P$ response patterns vary substantially among models. However, for each given model the change patterns for both SAT and $P$ do not vary much after the first 100 years or so, as reflected by the relatively high correlations shown in Fig. 13 between the final and an earlier 50-yr periods. For unknown reasons, 
(a) Normalized dT, RCP8.5, Year 2271-2300 mean

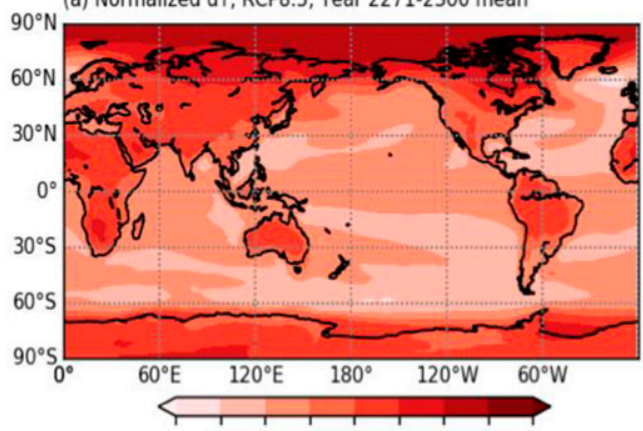

$\begin{array}{lllllllll}0.4 & 0.6 & 0.8 & 1.0 & 1.2 & 1.5 & 2.0 & 2.5 & 3.0\end{array}$

(c) Normalized dT, RCP8.5, Year 1971-2000 mean minus 2271-2300 mean

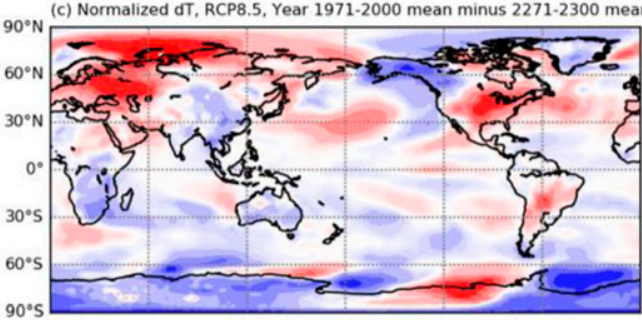

(e) Normalized dT, RCP8.5, Year 2071-2100 mean minus 2271-2300 mean

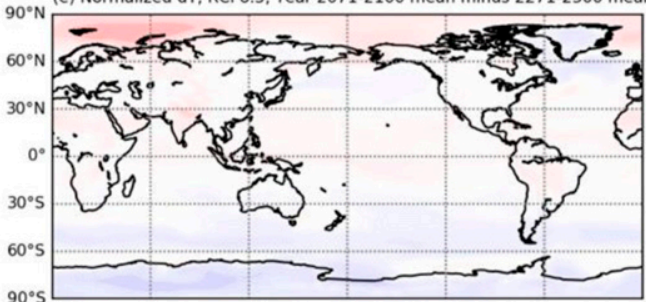

(g) Normalized dT, RCP8.5, Year 2171-2200 mean minus 2271-2300 mea

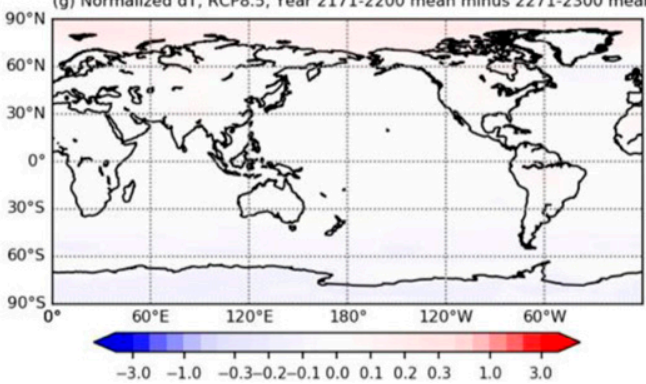

(b) Normalized dP, RCP8.5, Year 2271-2300 mean

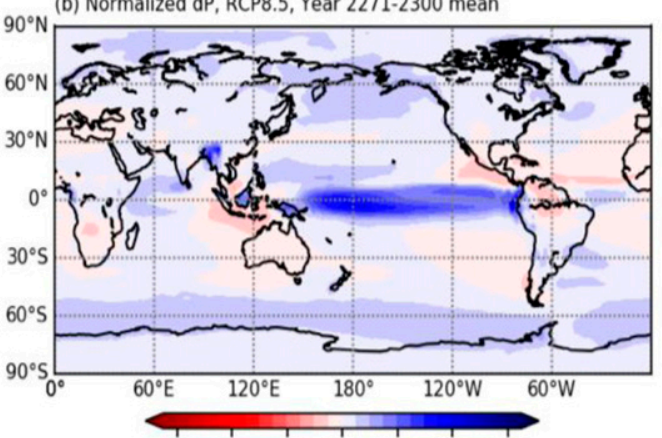

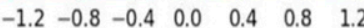

(d) Normalized dP, RCP8.5, Year 1971-2000 mean minus 2271-2300 mean
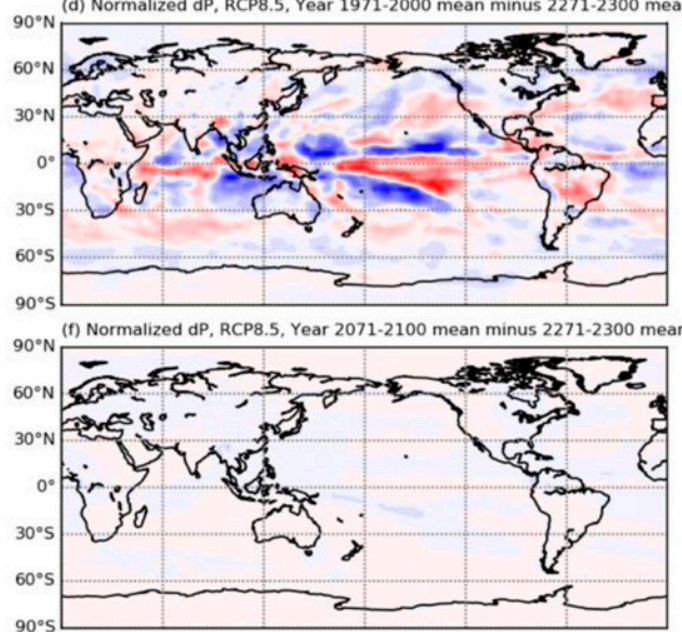

(h) Normalized dP, RCP8.5, Year 2171-2200 mean minus 2271-2300 mean

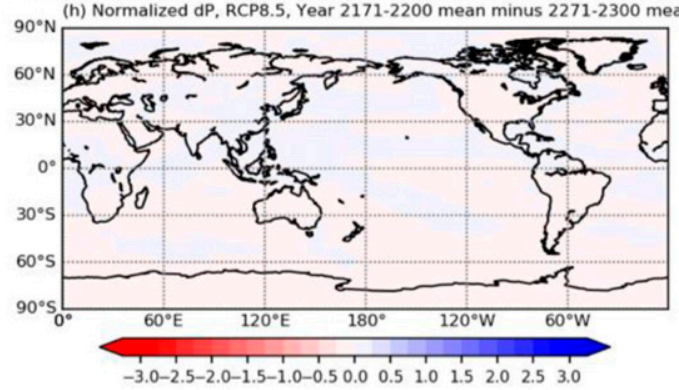

FIG. 9. Normalized change patterns for annual (a) surface air temperature (K per $1 \mathrm{~K}$ of global warming) and (b) precipitation $\left(\mathrm{mm} \mathrm{day}^{-1}\right.$ per $1 \mathrm{~K}$ of global warming) from the ensemble mean of the nine CMIP5 models listed in Table 1 under the ECP8.5 emissions scenario for years 2271-2300; and the differences in the normalized changes for annual (c),(e),(g) surface air temperature and (d),(f),(h) precipitation between years (c),(d) 1971-2000 and 2271-2300, (e),(f) 2071-2100 and 2271-2300, and (g),(h) 2171-2200 and 2271-2300. The future changes are relative to the 1970-99 mean. The pattern correlation coefficient between (a) and the normalized temperature change averaged over 1971-2000, 2071-2100, and 2171-2200 is $0.53,0.96$, and 0.99 , respectively. The pattern correlation coefficient between (b) and the normalized precipitation change averaged over 1971-2000, 2071-2100, and 21712200 is $0.03,0.90$, and 0.98 , respectively.

the GISS-E2-R, which shows some abrupt fluctuations (Fig. 10c), exhibits stronger pattern correlations for $P$ than for SAT (Fig. 13).

Nevertheless, the southern mid- to high latitudes and the northern North Atlantic show less warming during the transient period than the final period, while it is the opposite for the Arctic and most continents in all the models (Fig. 11e, with weaker early warming over the Arctic in CESM1.2.1). The difference maps from the long simulations are similar to Fig. 9c for the CMIP5 ensemble-mean SAT, and Fig. $2 \mathrm{~g}$ from the CESM1.2.1 $2 \times \mathrm{CO}_{2}$ experiment. However, the first 51 years in the 

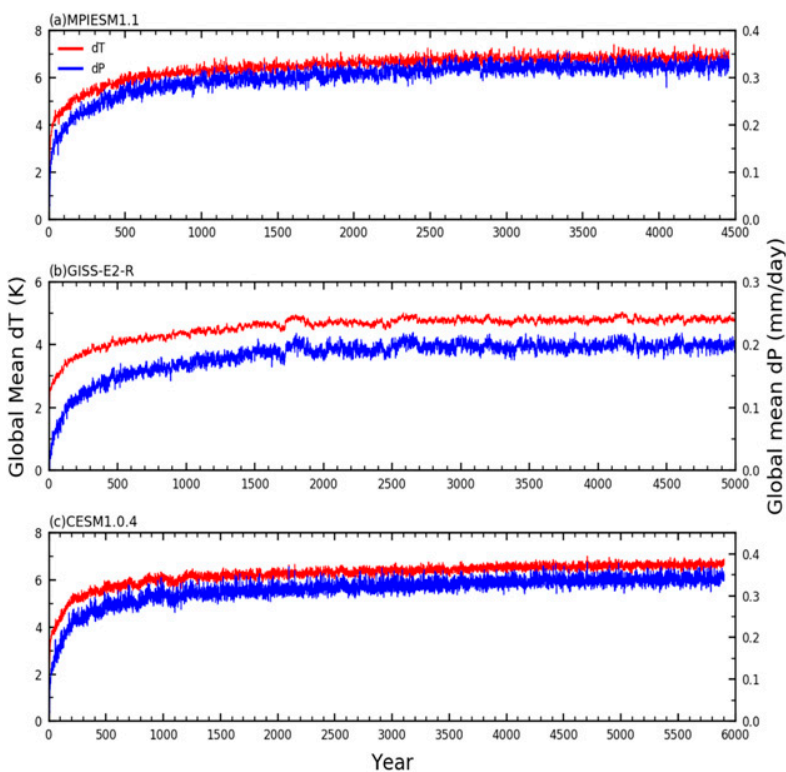

FIG. 10. Time series of annual global-mean surface air temperature (red; left $y$ axis) and precipitation (blue; right $y$ axis) changes (relative to the PiControl climatology) from the $4 \times \mathrm{CO}_{2}$ experiment using (a) MPI-ESM-1.1, (b) GISS-E2-R, and (c) CESM1.0.4. The simulation length for MPI-ESM-1.1, GISS-E2-R, and CESM1.0.4 is 4458,5000 , and 5900 years, respectively.

CESM1.2.1 experiments show weaker warming over the Arctic (Figs. 2d-f), which is also seen in the first 50 years of the CESM1.0.4 long simulation but not for the other two models (figure not shown).

Further examination of the difference maps from the abrupt $4 \times \mathrm{CO}_{2}$ multi-millennium simulations revealed that during the first few hundred years, the temporal differences for the SAT change come mainly from the Arctic, the northern North Atlantic, Eurasia and North America, the Southern Ocean, and Antarctica, whereas the differences for the $P$ change are mainly seen over the tropics and northwestern Pacific. Below we examine these regional features further.

Figure 14 shows the smoothed temporal evolutions of the Artic amplification (AA) - the ratio of the Arctic (north of $67^{\circ} \mathrm{N}$ ) versus global-mean surface warming rates (e.g., Screen and Simmonds 2010; Serreze and Barry 2011) - together with Arctic sea ice declines in the three long simulations. As Arctic sea ice cover (SIC) decreases rapidly during the first 200 years, AA increases in CESM1.0.4 or stays at a high level in MPIESM-1.1 and GISS-E2-R; however, as SIC decreases to a low constant value (which seems too high in GISS-E2-R), AA stays around a level similar to that in the first 200 years in CESM1.0.4 but decreases to a lower level in the other two models. This suggests different responses of Arctic SAT during the transient and equilibrium states for MPI-ESM-1.1 and GISS-E2-R but the responses are similar for CESM1.0.4. These Arctic SAT response differences are confirmed by their SAT difference maps (cf. Fig. 11; not shown for GISS-E2-R and CESM1.0.4). On centennial time scales, the AA and SIC variations are negatively correlated, with higher AA associated with lower SIC in all the three models.

Another robust warming feature is the land-ocean contrast (LOC), which shows larger warming over land than over ocean in both transient and equilibrium climate response to increased $\mathrm{CO}_{2}$ (Sutton et al. 2007; Joshi et al. 2007, 2013; Dong et al. 2009). Here we define the LOC as the ratio of the SAT change between the land and ocean areas within $60^{\circ} \mathrm{S}-60^{\circ} \mathrm{N}$. Figure 15 shows that in all the three models, the LOC peaks and may exceed 1.6 at the beginning the simulation (as land responds faster to $\mathrm{CO}_{2}$ forcing than ocean), decreases rapidly during the first $100-200$ years, and continue to decline slowly until about year 1000; thereafter, the annual LOC stays around 1.35 for MPI-ESM-1.1 and GISS-E2-R and around 1.29 for CESM1.0.4, with JJA having a higher LOC. Thus, the land-ocean warming contrast decreases over time during the transient period and stabilizes after about year 1000 but still remains considerably in the near-equilibrium state, consistent with the previous studies cited above. The LOC under increasing $\mathrm{CO}_{2}$ has been linked to local feedbacks and the hydrological cycle over land (Joshi et al. 2007) and different properties of the surface and boundary layer over land and ocean (Joshi et al. 2013).

Another regional warming feature is the North Atlantic warming hole (NAWH) - the relatively small warming over the central subpolar North Atlantic Ocean compared with nearby ocean areas (Gervais et al. 2018). The NAWH has been linked to a slowdown of the Atlantic meridional overturning circulation (e.g., Rahmstorf et al. 2015; Gervais et al. 2018), which results in a reduced ocean heat transport and increased cold advection (Dai et al. 2005) into the warming hole regions. Recently, Keil et al. (2020) found that the changes in the gyre circulation increases ocean heat transport into higher latitudes and contributes to the NAWH. Figure 16 shows that, similar to the land-ocean warming contrast, the NAWH is largest (with no warming over $45^{\circ}-60^{\circ} \mathrm{N}, 60^{\circ}-40^{\circ} \mathrm{W}$ during DJF in GISS-E2-R) during the first 100 years or so and then decreases from years 100 to 200 rapidly and then gradually until about year 1500; thereafter, the NAWH remains weak (i.e., close to 1). In other words, the NAWH is a feature that exists mainly in the transient period (the first 1000 years) and it largely disappears as the system approaches a new equilibrium. The NAWH is largest in DJF and smallest in JJA (Fig. 16), the opposite to the land-ocean contrast (Fig. 15). We further compared the LOC over $60^{\circ} \mathrm{S}-60^{\circ} \mathrm{N}, 0^{\circ}-60^{\circ} \mathrm{N}, 0^{\circ}-60^{\circ} \mathrm{S}$, and $20^{\circ} \mathrm{S}-20^{\circ} \mathrm{N}$, and found that the rapid decrease in global LOC 
(a) Normalized dT, Year 301-350 mean

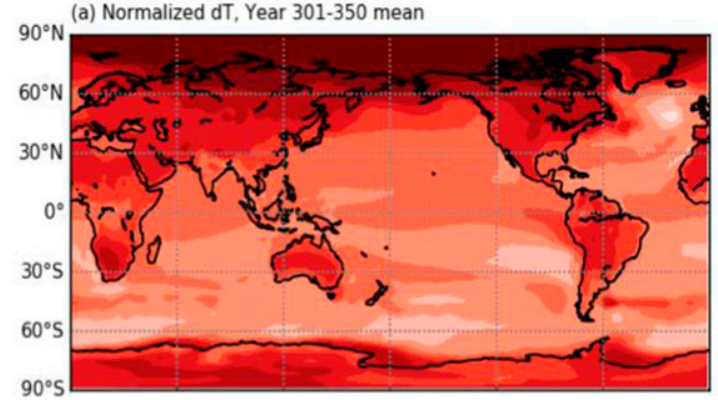

(c) Normalized dT, Year 4408-4458 mean
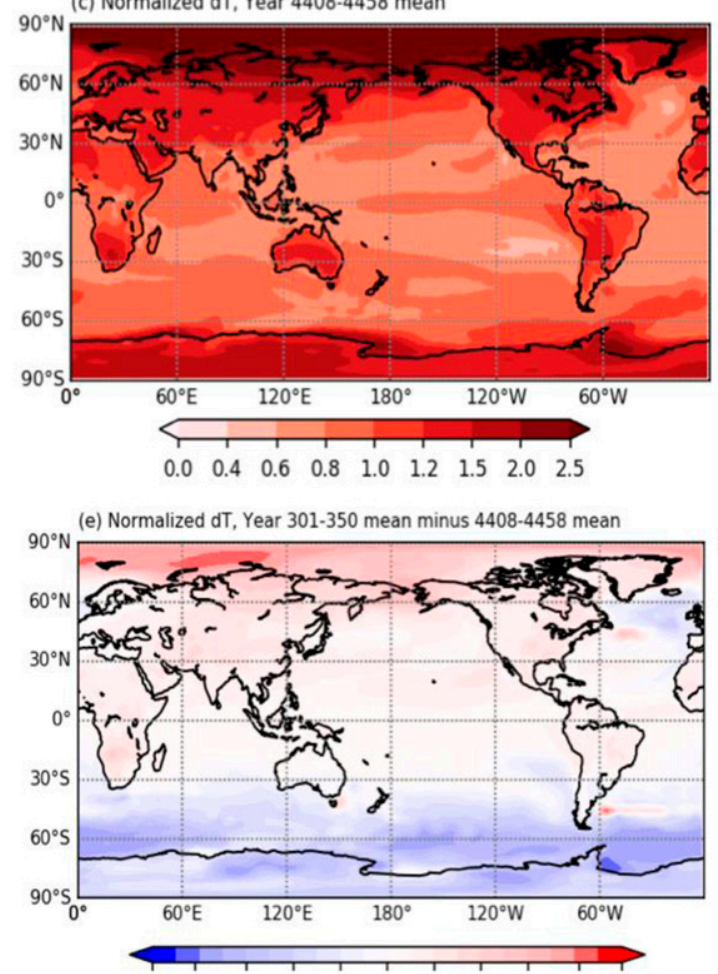

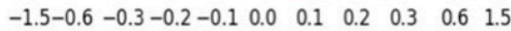

(b) Normalized dP,Year 301-350 mean

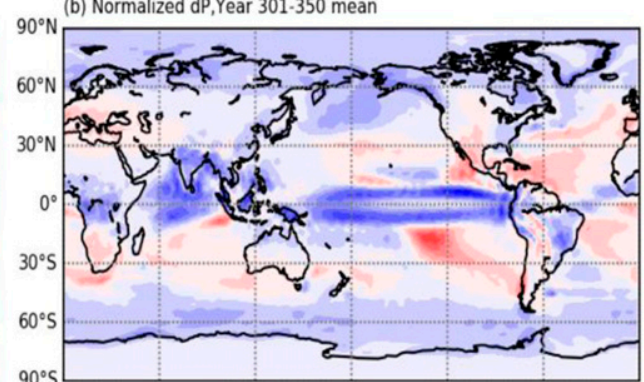

(d) Normalized dP,Year $4408-4458$ mean

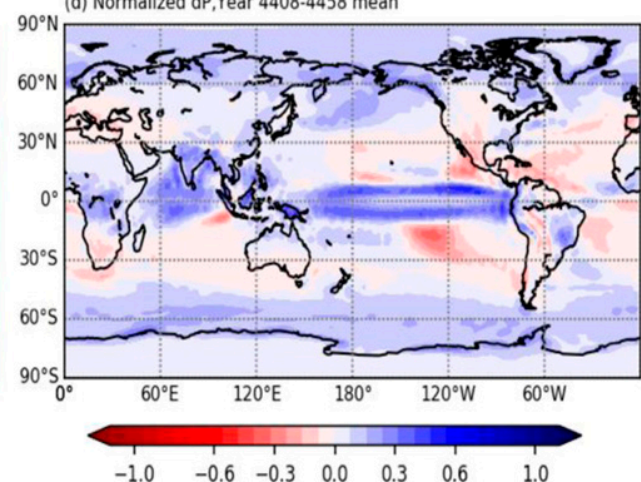

(f) Normalized dP, Year 301-350 mean minus 4408-4458 mean

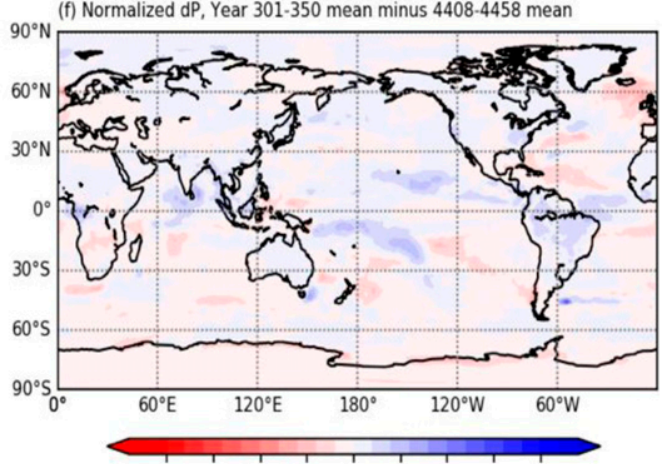

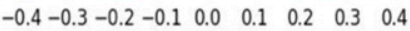

FIG. 11. Normalized annual (a),(c) surface air temperature (K per $1 \mathrm{~K}$ of global warming) and (b),(d) precipitation (mm day ${ }^{-1}$ per $1 \mathrm{~K}$ of global warming) change patterns averaged over years (a),(b) 301-350 and (c), (d) 44084458 , and (e),(f) the differences between years 301-350 and 4408-4458 from the $4 \times \mathrm{CO}_{2}$ experiment using the MPI-ESM-1.1 model. The pattern correlation coefficients between (a) and (c) and between (b) and (d) are 0.96 and 0.97, respectively. All the changes are relative to the PiControl run climatology.

during the first 200 years is mostly due to the initial slow warming of the Southern Ocean rather than the NAWH (not shown).

Figure 17 shows the temporal evolution of the AA, LOC, and NAWH in the transient CESM $11 \% \mathrm{CO}_{2}$ experiment and CMIP5 ECP8.5 runs. In the $1 \% \mathrm{CO}_{2}$ experiment, the AA fluctuates considerably during the first 70 years but then stabilizes around a value of 2.40; the LOC decreases sharply during the first 50 years and then stabilizes around a value of 1.45; and the NAWH strengthens during the first 60 years and then weakens until the end of the simulation. The AA and LOC increase monotonically until about 2080 and then decrease steadily in the CMIP5 ECP8.5 simulations, while the NAWH is relatively stable and weakens slightly from $\sim 0.94$ to 0.97 (Fig. 17). The temporal evolutions in the CMIP5 runs may be linked to their external forcing characteristics, which show a rapid increase in the twenty-first century, a slow increase in the twenty-second century, and then stability in the twenty-third century (van Vuuren et al. 2011). Nevertheless, the general behaviors of the AA, LOC, and NAWH in these transient simulations are qualitatively consistent with those seen in the long $4 \times \mathrm{CO}_{2}$ runs (Figs. 14-16), and all of them show steady weakening toward the end of the simulations. The AA, LOC, and 

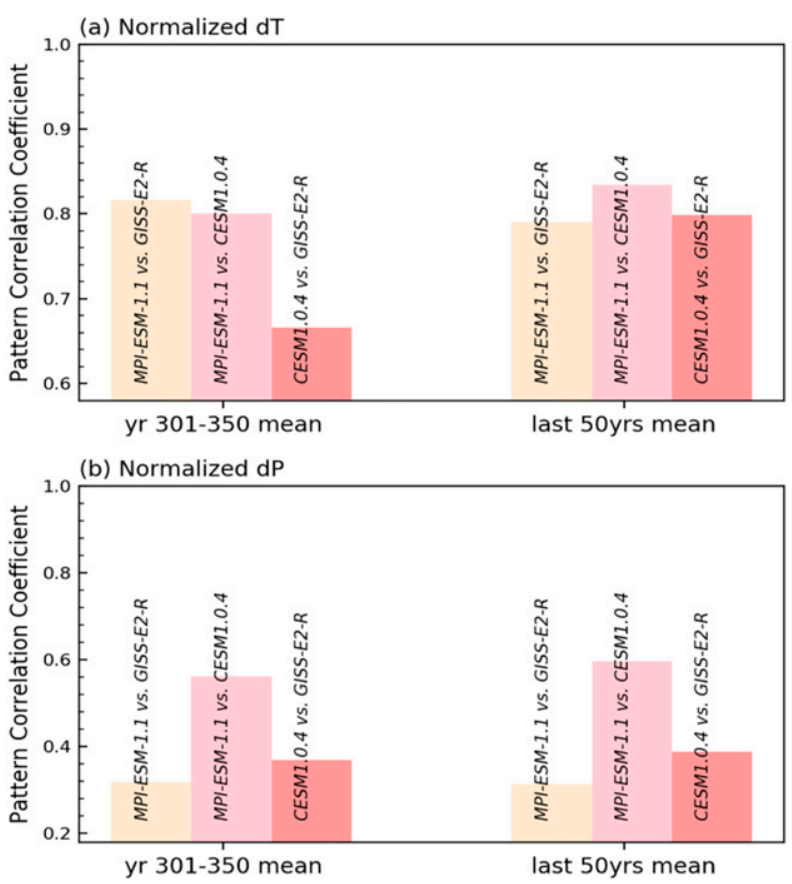

FIG. 12. The pattern correlation coefficients of the normalized annual (a) surface air temperature and (b) precipitation changes over the globe between the different models in the same period (the year 301-350 and the last 50 years) from the three abrupt $4 \times$ $\mathrm{CO}_{2}$ multi-millennium simulations. Using 100-yr averages yielded similar results.

NAWH values near the end of the simulations (last 50-yr average) are 2.40, 1.46, and 0.68 , respectively, for the CESM1 $1 \% \mathrm{CO}_{2}$ experiment, and 1.91, 1.46, and 0.97 for the ECP8.5 ensemble mean. These values are broadly comparable to the abrupt $4 \times \mathrm{CO}_{2}$ multi-millennium simulations (Figs. 14-16).

\section{Conclusions and discussion}

We have compared the normalized change patterns for annual and seasonal surface air temperature (SAT) and precipitation $(P)$ in response to increasing $\mathrm{CO}_{2}$ over different time periods and across different forcing scenarios $\left(2 \times \mathrm{CO}_{2}, 4 \times \mathrm{CO}_{2}\right.$, and $1 \%$ $\mathrm{CO}_{2}$ ) using long-term simulations by the CESM1.2.1, together with those from the CMIP5 extended RCP8.5 simulations and abrupt $4 \times \mathrm{CO}_{2}$ multi-millennium simulations from three other coupled models. Results show that the normalized SAT annual and seasonal change patterns per unit global warming vary little over time after the first 100 years or so and among different experiments, and the transient change patterns are close to those approximately representing an equilibrium response. The consistency of the warming patterns
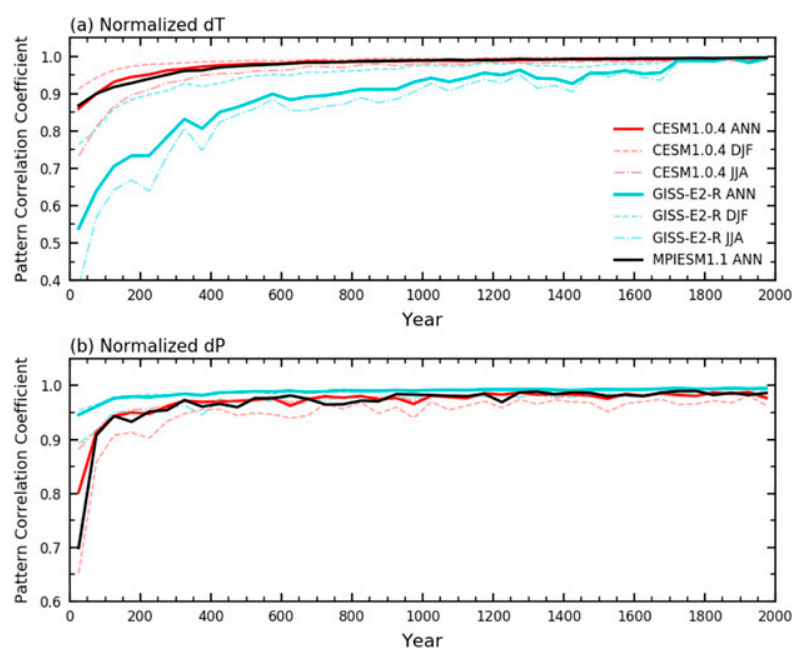

FIG. 13. Temporal variations in the pattern correlation coefficients $(r)$ of the 50-yr-averaged, normalized annual (solid lines) and seasonal (DJF and JJA; dashed lines) (a) surface air temperature and (b) precipitation changes over the globe between the last 50 years and a 50-yr period centered at the plotted year on the $x$ axis from the $4 \times \mathrm{CO}_{2}$ experiment using MPI-ESM1.1, GISS-E2-R, and CESM1.0.4. The $r$ values do not change much after year 1975.

during the first 200 years is stronger over land than over ocean, but is lower in midlatitudes than other regions. This is also true for precipitation change patterns, albeit to a lesser degree. Precipitation over many subtropical
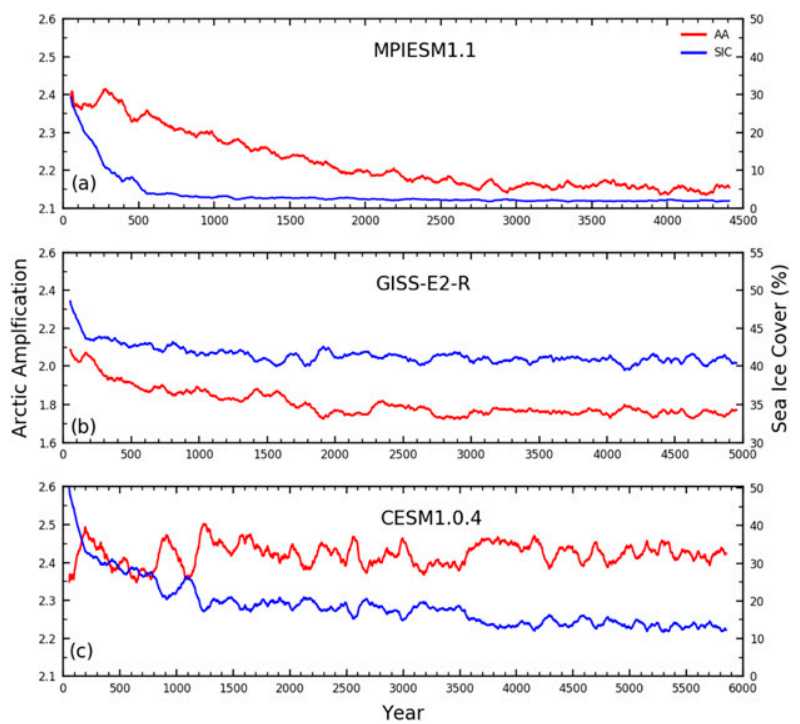

FIG. 14. The 101-yr moving-average time series of the Arctic amplification (AA; red line) and Arctic sea ice cover (SIC; in \% of Arctic oceanic area) (blue line; on the right $y$ axis) from the $4 \times \mathrm{CO}_{2}$ experiment using (a) MPI-ESM-1.1, (b) GISS-E2-R, and (c) CESM1.0.4. The AA is defined as Arctic (north of $67^{\circ} \mathrm{N}$ ) surface air temperature change ( $d T$; relative to PiControl) divided by global-mean $d T$, and it stays around 2.16, 1.77, and 2.44 near the end of the simulation in MPI-ESM-1.1, GISSE2-R, and CESM1.0.4 respectively. 

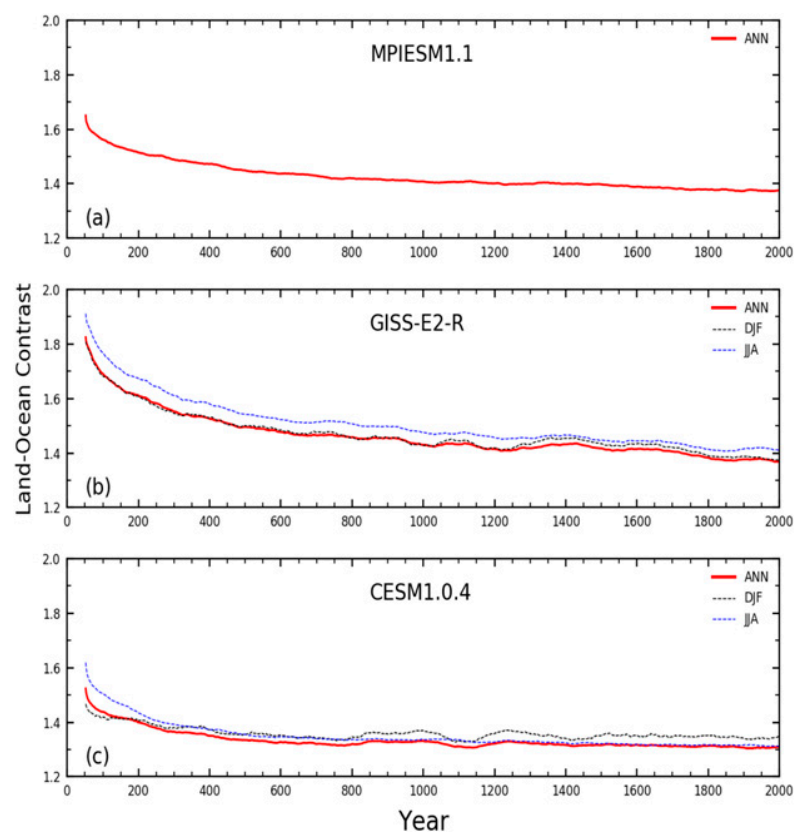

FIG. 15. The 101-yr moving-average time series of the landocean contrast (LOC) of surface warming from the $4 \times \mathrm{CO}_{2}$ experiment using (a) MPI-ESM-1.1, (b) GISS-E2-R, and (c) CESM1.0.4. The values do not change much after year 2000. The LOC is defined as $60^{\circ} \mathrm{S}-60^{\circ} \mathrm{N}$ mean land surface air temperature change ( $d T$; relative to PiControl) divided by $60^{\circ} \mathrm{S}-60^{\circ} \mathrm{N}$ mean ocean $d T$. The two dashed lines in (b) and (c) indicate the DJF and JJA mean time series of the LOC (seasonal data are unavailable for MPI-ESM-1.1). The annual LOC near the end of the simulations is 1.35, 1.35, and 1.29 in MPI-ESM-1.1, GISS-E2-R, and CESM1.0.4, respectively.

oceans and land areas decreases consistently under different forcing scenarios and over all time periods.

Some differences exist during the early transient period (the first few hundred years) and the final period. For the normalized SAT change, warming over the northern North Atlantic and parts of the Southern Ocean is weaker during the early period (especially the first 50 years) than during the final period. In contrast, the normalized warming over most continents is stronger in the early period, while the early normalized warming over the Arctic is weaker in the CESM1 but stronger in the CMIP5 ensemble mean, MPI-ESM-1.1 and GISS-E2-R than that in the final period. For the normalized $P$ changes, noticeable differences exist over tropical oceans with smaller early increases over the tropical Pacific.

The abrupt $4 \times \mathrm{CO}_{2}$ multi-millennium simulations further indicate that the Arctic amplification, land-ocean warming contrast, and North Atlantic warming hole (NAWH) are largest during the first 100-200 years; thereafter, they decrease and stabilize after year $\sim 500$, with the NAWH becoming weak after year $\sim 1500$. Thus, the NAWH is mainly a transient feature in

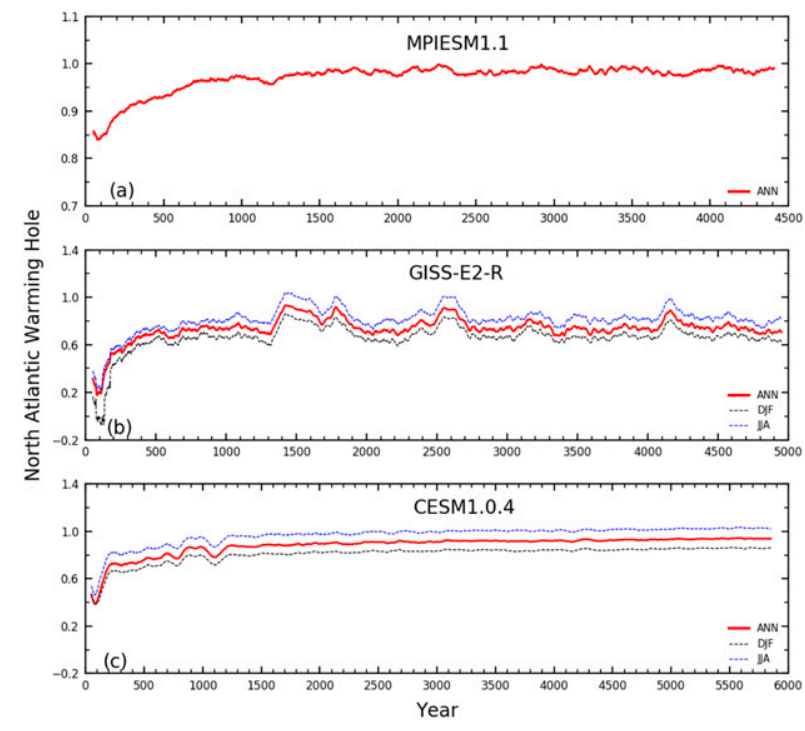

FIG. 16. As in Fig. 15, but for the North Atlantic warming hole (NAWH). The NAWH is defined as the mean oceanic surface air temperature change ( $d T$, relative to PiControl) averaged over the region $45^{\circ}-60^{\circ} \mathrm{N}, 60^{\circ}-40^{\circ} \mathrm{W}$ divided by the mean oceanic $d T$ over the region $39^{\circ}-66^{\circ} \mathrm{N}, 70^{\circ}-30^{\circ} \mathrm{W}$ (but excluding $45^{\circ}-60^{\circ} \mathrm{N}, 60^{\circ}-$ $40^{\circ} \mathrm{W}$ ). The two dashed lines in (b) and (c) indicate the DJF and JJA mean time series of the NAWH. The annual NAWH near the end of the simulations is $0.99,0.73$, and 0.94 in MPI-ESM-1.1, GISSE2-R, and CESM1.0.4, respectively.

response to $\mathrm{CO}_{2}$ forcing, while all the other features, including the larger warming in the Arctic and over land and the subtropical drying, exist in both the transient period and the equilibrium state, albeit with varying magnitudes.

As discussed in the introduction, previous studies (e.g., Armour et al. 2013; Andrews et al. 2015; Yoshimori et al. 2016; Paynter et al. 2018) have shown considerable differences in regional SAT changes (mostly over high latitudes) in response to abrupt $\mathrm{CO}_{2}$ forcing among the decades of the first 100 years or so. This is expected given the rapid adjustments during the early decades after an abrupt doubling or quadrupling of atmospheric $\mathrm{CO}_{2}$, and the large internal variability on regional scales for decadal climates (Dai and Bloecker 2019). In other words, those differences likely partly resulted from the significant influence from random internal variability on local and regional SAT and $P$ when averages over a few decades were used. Our results show that, when averaged over 50 years or longer or over multimodel ensemble runs (which greatly reduces internal variability), the SAT and $P$ change patterns in response to either abrupt or gradual $\mathrm{CO}_{2}$ increases are broadly similar, with the main characteristics persisting over time and across different types of experiments, although the normalized magnitude may change over time. One exception is the NAWH, which is 

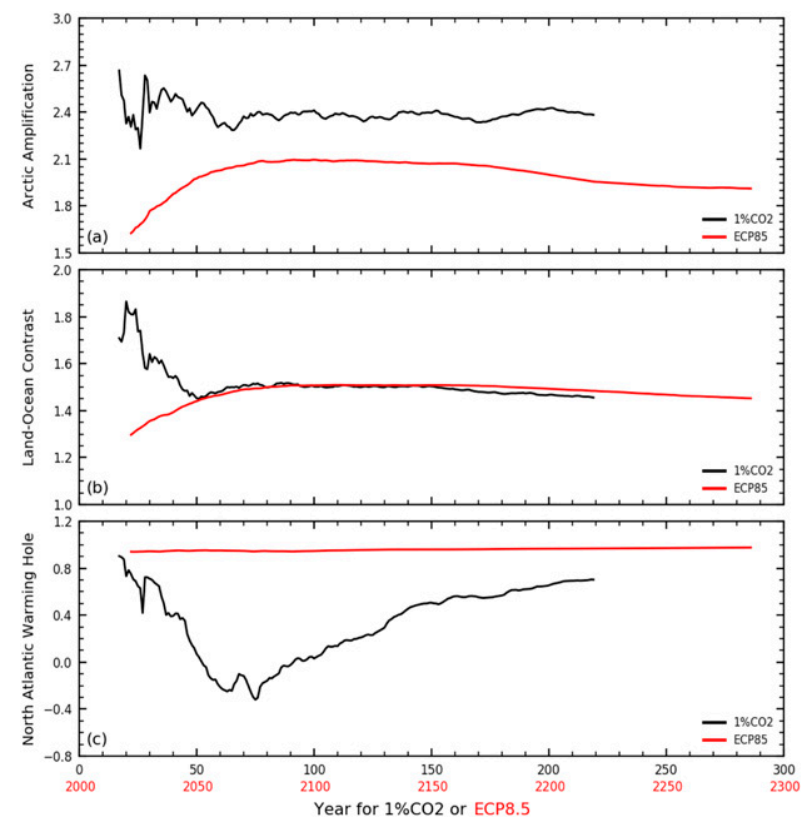

FIG. 17. The 31-yr moving-average time series of the (a) AA, (b) LOC, and (c) NAWH from the CESM1 $1 \% \mathrm{CO}_{2}$ experiment and the ensemble mean of nine CMIP5 models listed in Table 1 under the ECP8.5 emissions scenario. The definitions of the AA, LOC, and NAWH are as in Figs. 14-16, respectively. The black and red labels on the $x$ axis indicate the model years for the CESM1 $1 \%$ $\mathrm{CO}_{2}$ run and ECP8.5 simulations, respectively.

mainly a transient response. We should also notice that the change patterns are likely to be more complicated for extreme events (Lustenberger et al. 2014), due to certain feedbacks in some specific regions (Fischer and Schär 2009). Furthermore, while the regional differences in the response patterns may be small, they could still have significant impacts in certain fields.

Acknowledgments. We thank Xiucheng Xiao, Peiwen Yan, and Jiao Chen from Nanjing University for downloading some of the CMIP5 model data and the references used or cited in this study. This study was jointly sponsored by the National Key Research and Development Program of China (Grant 2016YFA0600701) and the Jiangsu Collaborative Innovation Center for Climate Change. Dai acknowledges the funding support from the U.S. National Science Foundation (OISE-1743738), and the U.S. National Oceanic and Atmospheric Administration (Awards NA15OAR4310086 and NA18OAR4310425).

\section{REFERENCES}

Andrews, T., M. G. Jonathan, and J. W. Mark, 2015: The dependence of radiative forcing and feedback on evolving patterns of surface temperature change in climate models. J. Climate, 28, 1630-1648, https://doi.org/10.1175/JCLI-D-14-00545.1.
Armour, K. C., C. M. Bitz, and G. H. Roe, 2013: Time-varying climate sensitivity from regional feedbacks. J. Climate, 26, 4518-4534, https://doi.org/10.1175/JCLI-D-12-00544.1.

Barnes, E. A., and L. M. Polvani, 2015: CMIP5 projections of Arctic amplification, of the North American/North Atlantic circulation, and of their relationship. J. Climate, 28, 5254-5271, https://doi.org/10.1175/JCLI-D-14-00589.1.

Burls, N. J., and A. V. Fedorov, 2017: Wetter subtropics in a warmer world: Contrasting past and future hydrological cycles. Proc. Natl. Acad. Sci., 201703421, https://doi.org/10.1073/pnas.1703421114.

Chen, J., A. Dai, Y. Zhang, and K. L. Rasmussen, 2020: Changes in convective potential energy and convective inhibition under global warming. J. Climate, 33, 2025-2050, https://doi.org/ 10.1175/JCLI-D-19-0461.1.

Chou, C., J. D. Neelin, C. A. Chen, and J. Y. Tu, 2009: Evaluating the "rich-get-richer" mechanism in tropical precipitation change under global warming. J. Climate, 22, 1982-2005, https://doi.org/ 10.1175/2008JCLI2471.1.

Collins, M., and Coauthors, 2013: Long-term climate change: Projections, commitments and irreversibility. Climate Change 2013: The Physical Science Basis, T. F. Stocker et al., Eds., Cambridge University Press, 1029-1136.

Dai, A., and C. E. Bloecker, 2019: Impacts of internal variability on temperature and precipitation trends in large ensemble simulations by two climate models. Climate Dyn., 52, 289-306, https://doi.org/10.1007/s00382-018-4132-4.

— A. Hu, G. A. Meehl, W. M. Washington, and W. G. Strand, 2005: Atlantic thermohaline circulation in a coupled general circulation model: Unforced variations versus forced changes. J. Climate, 18, 3270-3293, https://doi.org/10.1175/JCLI3481.1.

— T. Thao, and J. Chen, 2018: Climate change and drought: A precipitation and evaporation perspective. Curr. Climate Change Rep., 4, 301-312, https://doi.org/10.1007/s40641-018-0101-6.

—, D. Luo, M. Song, and J. Liu, 2019: Arctic amplification is caused by sea-ice loss under increasing $\mathrm{CO}_{2}$. Nat. Commun., 10, 121, https://doi.org/10.1038/s41467-018-07954-9.

—, D. Huang, B. E. J. Rose, J. Zhu, and X. Tian, 2020a: Improved methods for estimating equilibrium climate sensitivity from transient warming simulations. Climate Dyn., 54, 4515-4543, https://doi.org/10.1007/s00382-020-05242-1.

— R. M. Rasmussen, C. Liu, K. Ikeda, and A. F. Prein, 2020b: A new mechanism for warm-season precipitation response to global warming based on convection-permitting simulations. Climate Dyn., 55, 343-368, https://doi.org/10.1007/S00382-0173787-6.

Deser, C., A. Phillips, V. Bourdette, and H. Teng, 2012: Uncertainty in climate change projections: The role of internal variability. Climate Dyn., 38, 527-546, https://doi.org/10.1007/s00382-010-0977-x.

Dong, B., J. M. Gregory, and R. T. Sutton, 2009: Understanding land-sea warming contrast in response to increasing greenhouse gases. Part I: Transient adjustment. J. Climate, 22, 30793097, https://doi.org/10.1175/2009JCLI2652.1.

Fischer, E. M., and C. Schär, 2009: Future changes in daily summer temperature variability: Driving processes and role for temperature extremes. Climate Dyn., 33, 917, https://doi.org/10.1007/ s00382-008-0473-8.

Geoffroy, O., and D. Saint-Martin, 2014: Pattern decomposition of the transient climate response. Tellus, 66A, 23393, https:// doi.org/10.3402/tellusa.v66.23393.

Gervais, M., J. Shaman, and Y. Kushnir, 2018: Mechanisms governing the development of the North Atlantic warming hole in the CESM-LE future climate simulations. J. Climate, 31, 59275946, https://doi.org/10.1175/JCLI-D-17-0635.1. 
Hawkins, E., and R. Sutton, 2011: The potential to narrow uncertainty in projections of regional precipitation change. Climate Dyn., 37, 407-418, https://doi.org/10.1007/s00382-010-0810-6.

He, J., and B. J. Soden, 2016: A re-examination of the projected subtropical precipitation decline. Nat. Climate Change, $\mathbf{7}$, 53-57, https://doi.org/10.1038/nclimate3157.

Held, I. M., and B. J. Soden, 2006: Robust responses of the hydrological cycle to global warming. J. Climate, 19, 5686-5699, https://doi.org/10.1175/JCLI3990.1.

Holland, M. M., and C. M. Bitz, 2003: Polar amplification of climate change in coupled models. Climate Dyn., 21, 221-232, https:// doi.org/10.1007/s00382-003-0332-6.

Huang, D., J. Zhu, Y. Zhang, and A. Huang, 2013: Uncertainties on the simulated summer precipitation over eastern China from the CMIP5 models. J. Geophys. Res. Atmos., 118, 9035-9047, https://doi.org/10.1002/JGRD.50695.

_- P. Yan, J. Zhu, Y. Zhang, X. Kuang, and J. Cheng, 2018: Uncertainty of global summer precipitation in the CMIP5 models: A comparison between high-resolution and lowresolution models. Theor. Appl. Climatol., 132, 55-69, https:// doi.org/10.1007/s00704-017-2078-9.

Hurrell, J. W., and Coauthors, 2013: The Community Earth System Model: A framework for collaborative research. Bull. Amer. Meteor. Soc., 94, 1339-1360, https://doi.org/10.1175/BAMS-D-12-00121.1.

Ishizaki, Y., and Coauthors, 2012: Temperature scaling pattern dependence on representative concentration pathway emission scenarios. Climatic Change, 112, 535-546, https://doi.org/10.1007/ s10584-012-0430-8.

Joshi, M. M., J. M. Gregory, M. J. Webb, D. M. H. Sexton, and T. C. Johns, 2007: Mechanisms for the land/sea warming contrast exhibited by simulations of climate change. Climate Dyn., $\mathbf{3 0}$, 455-465, https://doi.org/10.1007/s00382-007-0306-1.

_ , F. H. Lambert, and M. J. Webb, 2013: An explanation for the difference between twentieth and twenty-first century landsea warming ratio in climate models. Climate Dyn., 41, 18531869, https://doi.org/10.1007/s00382-013-1664-5.

Keil, P., T. Mauritsen, J. Jungclaus, C. Hedemann, D. Olonscheck, and R. Ghosh, 2020: Multiple drivers of the North Atlantic warming hole. Nat. Climate Change, 10, 667-671, https:// doi.org/10.1038/s41558-020-0819-8.

Kiehl, J. T., 2007: Twentieth century climate model response and climate sensitivity. Geophys. Res. Lett., 34, L22710, https:// doi.org/10.1029/2007GL031383.

Leduc, M., H. Damon Matthews, and R. De Elía, 2016: Regional estimates of the transient climate response to cumulative $\mathrm{CO}_{2}$ emissions. Nat. Climate Change, 6, 474-478, https://doi.org/ 10.1038/nclimate2913.

Lustenberger, A., R. Knutti, and E. M. Fischer, 2014: The potential of pattern scaling for projecting temperature-related extreme indices. Int. J. Climatol., 34, 18-26, https://doi.org/10.1002/joc.3659.

Manabe, S., and R. J. Stouffer, 1994: Multiple-century response of a coupled ocean-atmosphere model to an increase of atmospheric carbon dioxide. J. Climate, 7, 5-23, https://doi.org/ 10.1175/1520-0442(1994)007<0005:MCROAC >2.0.CO;2.

_- M. J. Spelman, R. J. Stouffer, and K. Bryan, 1992: Transient responses of a coupled ocean-atmosphere model to gradual changes of atmospheric $\mathrm{CO}_{2}$. Part I: Annual mean response. J. Climate, 5, 105-126, https://doi.org/10.1175/1520-0442(1992) 005<0105:TROACO $>2.0$. CO;2.

Meehl, G. A., W. M. Washington, J. M. Arblaster, and A. Hu, 2004: Factors affecting climate sensitivity in global coupled models. J. Climate, 17, 1584-1596, https://doi.org/10.1175/1520-0442(2004) $017<1584$ :FACSIG $>2.0$. CO;2.
,-- , W. D. Collins, J. M. Arblaster, A. Hu, L. W. Buja, W. G. Strand, and H. Teng, 2005: How much more global warming and sea level rise? Science, 307, 1769-1772, https://doi.org/ 10.1126/science.1106663.

Meinshausen, M., and Coauthors, 2011: The RCP greenhouse gas concentrations and their extensions from 1765 to 2300. Climatic Change, 109, 213-241, https://doi.org/10.1007/s10584-011-0156-z.

Mitchell, J. F. B., S. Manabe, V. Meleshko, and T. Tokioka, 1990: Equilibrium climate change-and its implications for the future. Climate Change: The IPCC Scientific Assessment, J. L. Houghton, G. J. Jenkins, and J. J. Ephraums, Eds., Cambridge University Press, 131-172.

Mortin, J., G. Svensson, R. G. Graversen, M.-L. Kapsch, J. C. Stroeve, and L. N. Boisvert, 2016: Melt onset over Arctic sea ice controlled by atmospheric moisture transport. Geophys. Res. Lett., 43, 6636-6642, https://doi.org/10.1002/2016GL069330.

Paynter, D., T. L. Frölicher, L. W. Horowitz, and L. G. Silvers, 2018: Equilibrium climate sensitivity obtained from multimillennial runs of two GFDL climate models. J. Geophys. Res. Atmos., 123, 19211941, https://doi.org/10.1002/2017JD027885.

Pithan, F., and T. Mauristen, 2014: Arctic amplification dominated by temperature feedbacks in contemporary climate models. Nat. Geosci., 7, 181-184, https://doi.org/10.1038/ngeo2071.

Rahmstorf, S., J. E. Box, G. Feulner, M. E. Mann, A. Robinson, S. Rutherford, and E. J. Schaffernicht, 2015: Exceptional twentieth-century slowdown in Atlantic Ocean overturning circulation. Nat. Climate Change, 5, 475-480, https://doi.org/ 10.1038/nclimate2554.

Rose, B. E. J., and L. Rayborn, 2016: The effects of ocean heat uptake on transient climate sensitivity. Curr. Climate Change Rep., 2, 190-201, https://doi.org/10.1007/s40641-016-0048-4.

- K. C. Armour, D. S. Battisti, N. Feldl, and D. D. B. Koll, 2014: The dependence of transient climate sensitivity and radiative feedbacks on the spatial pattern of ocean heat uptake. Geophys. Res. Lett., 41, 1071-1078, https://doi.org/10.1002/ 2013 GL058955.

Rugenstein, A., and Coauthors, 2019: LongRunMIP: Motivation and design for a large collection of millennial-length AOGCM simulations. Bull. Amer. Meteor. Soc., 100, 2551-2570, https:// doi.org/10.1175/BAMS-D-19-0068.1.

Santer, B. D., T. M. L. Wigley, M. E. Schlesinger, and J. F. B. Mitchell, 1990: Developing climate scenarios from equilibrium GCM results. Max-Planck-Institut für Meteorologie Rep. 47, 29 pp., https:// www.mpimet.mpg.de/fileadmin/publikationen/Reports/Report_ 47.pdf.

Scheff, J., and D. M. W. Frierson, 2012a: Twenty-first-century multimodel subtropical precipitation declines are mostly midlatitude shifts. J. Climate, 25, 4330-4347, https://doi.org/ 10.1175/JCLI-D-11-00393.1.

$\longrightarrow$, and — 2012b: Robust future precipitation declines in CMIP5 largely reflect the poleward expansion of model subtropical dry zones. Geophys. Res. Lett., 39, L18704, https:// doi.org/10.1029/2012GL052910.

Screen, J., and I. Simmonds, 2010: The central role of diminishing sea ice in recent Arctic temperature amplification. Nature, 464, 1334-1337, https://doi.org/10.1038/nature09051.

Serreze, M. C., and J. A. Francis, 2006: The Arctic amplification debate. Climatic Change, 76, 241-264, https://doi.org/10.1007/ s10584-005-9017-y.

— plification: A research synthesis. Global Planet. Change, 77, 85-96, https://doi.org/10.1016/j.gloplacha.2011.03.004.

Sun, Y., S. Solomon, A. Dai, and R. W. Portmann, 2007: How often will it rain? J. Climate, 20, 4801-4818, https://doi.org/10.1175/JCLI4263.1. 
Sutton, R. T., B.-W. Dong, and J. M. Gregory, 2007: Land/sea warming ratio in response to climate change: IPCC AR4 model results and comparison with observations. Geophys. Res. Lett., 34, L02701, https://doi.org/10.1029/2006GL028164.

Taylor, K. E., R. J. Stouffer, and G. Meehl, 2012: An overview of CMIP5 and the experiment design. Bull. Amer. Meteor. Soc., 93, 485-498, https://doi.org/10.1175/BAMS-D-11-00094.1.

Tebaldi, C., and J. M. Arblaster, 2014: Pattern scaling: Its strengths and limitations, and an update on the latest model simulations. Climatic Change, 122, 459-471, https://doi.org/10.1007/s10584-013-1032-9.

Trenberth, K. E., A. Dai, R. M. Rasmussen, and D. B. Parsons, 2003: The changing character of precipitation. Bull. Amer. Meteor. Soc., 84, 1205-1218, https://doi.org/10.1175/BAMS84-9-1205. van Vuuren, D. P., and Coauthors, 2011: The representative concentration pathways: An overview. Climatic Change, 109, 5-31, https://doi.org/10.1007/s10584-011-0148-z.

Yoshimori, M., M. Watanabe, H. Shiogama, A. Oka, A. AbeOuchi, R. Ohgaito, and Y. Kamae, 2016: A review of progress towards understanding the transient global mean surface temperature response to radiative perturbation. Prog. Earth Planet. Sci., 3, 21, https://doi.org/10.1186/s40645-016-0096-3.

Zhang, M., 2011: Equilibrium and transient climate response to anthropogenic forcing: The impact of atmospheric feedback processes (in Chinese). Trans. Atmos. Sci., 34, 257-268.

Zhou, T., and X. Chen, 2015: Uncertainty in the $2^{\circ} \mathrm{C}$ warming threshold related to climate sensitivity and climate feedback. J. Meteor. Res., 29, 884-895, https://doi.org/10.1007/s13351-015-5036-4. 